\title{
Weather indicators and improving air quality in association with COVID-19 pandemic in India
}

\author{
Rabin Chakrabortty ${ }^{1} \cdot$ Subodh Chandra Pal ${ }^{1}$ (D) Manoranjan Ghosh ${ }^{2} \cdot$ Alireza Arabameri $^{3}$.

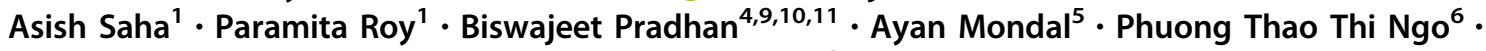 \\ Indrajit Chowdhuri ${ }^{1} \cdot$ Ali P. Yunus ${ }^{7} \cdot$ Mehebub Sahana $^{8} \cdot$ Sadhan Malik $^{1} \cdot$ Biswajit Das $^{1}$
}

Accepted: 28 June 2021 / Published online: 13 July 2021

(c) The Author(s), under exclusive licence to Springer-Verlag GmbH Germany, part of Springer Nature 2021

\begin{abstract}
The COVID-19 pandemic enforced nationwide lockdown, which has restricted human activities from March 24 to May 3 , 2020, resulted in an improved air quality across India. The present research investigates the connection between COVID-19 pandemic-imposed lockdown and its relation to the present air quality in India; besides, relationship between climate variables and daily new affected cases of Coronavirus and mortality in India during the this period has also been examined. The selected seven air quality pollutant parameters $\left(\mathrm{PM}_{10}, \mathrm{PM}_{2.5}, \mathrm{CO}, \mathrm{NO}_{2}, \mathrm{SO}_{2}, \mathrm{NH}_{3}\right.$, and $\left.\mathrm{O}_{3}\right)$ at 223 monitoring stations and temperature recorded in New Delhi were used to investigate the spatial pattern of air quality throughout the lockdown. The results showed that the air quality has improved across the country and average temperature and maximum temperature were connected to the outbreak of the COVID-19 pandemic. This outcomes indicates that there is no such relation between climatic parameters and outbreak and its associated mortality. This study will assist the policy maker, researcher, urban planner, and health expert to make suitable strategies against the spreading of COVID-19 in India and abroad.
\end{abstract}

Keywords COVID-19 $\cdot$ Air quality index $\cdot$ Lockdown $\cdot$ Mortality $\cdot$ Analytical neural network

\section{Introduction}

The epidemic has also sparked a worldwide economic catastrophe unlike any seen in the past decades, with ramifications that will last for years. The large proportion of our habits, commerce, social and economic ties, methods, modes of employment, and political institutions have already altered profoundly as a result of the epidemic (Boccaletti et al. 2020). The Coronavirus-induced lockdown has a remarkable influence on pollution in the world's second-largest populated country, India. Soon after the nationwide lockdown, ${ }^{1}$ the scientific community raised a question: Does the COVID-19 pandemic lockdown situation improve air quality, especially in cities and industrial corridors? (Wright 2020). The scattered empirical evidences have been suggested that paradoxically, the impact of the COVID-19 pandemic has improved air quality around the world, for instance, China, France, and

Communicated by Oscar Castillo.

Extended author information available on the last page of the article
Italy (Yunus et al. 2020) (ESA 2020). The National Aeronautics and Space Administration (NASA) has first reported that lockdown has reduced the aerosol and nitrogen dioxide over Wuhan in China (NASA 2020). Then, the European Space Agency (2020) had been continuously reported that in Italy, Spain, and France emissions reduced by 20 to $30 \%$ during the month of March 2020 due to the lockdown situation (ESA 2020). Tobías et al. 2020 found that air pollutant materials decreased significantly during the two-week lockdown period for example, $\mathrm{PM}_{10}$ decreased by $28 \%$ to $31.0 \%$, and nitrogen dioxide decreased by $45 \%$ to $51 \%$; on the contrary, ozone gas increased by $33 \%$ to $57 \%$ in Barcelona. During the prelocked down period, India had the top twenty polluted cities in the world (Majumdar et al. 2020) with the maximum cities that crossed the tolerant breathing limit of pure air in India (Central Pollution Control Board, 2019). Majumdar et al. 2020 also found that both particulate

\footnotetext{
${ }^{1}$ Indian lockdown is the world larges lockdown because of its population size and entire country wide lockdown at a time on March 24 to May 3, 2020. It is also the lockdown in world largest democracy.
} 
matters and gaseous pollutant have caused serious health problems in various cities in India, especially in Delhi, Kanpur, Kolkata, Bengaluru, and Mumbai. Balakrishnan 2019 found that in India, more than one million premature deaths have occurred due to various air pollutants. India has one of the utmost rates of respiratory problems and the world's maximum number of tuberculosis (Wright 2020). Garaga et al. 2018 estimated the regional average concentration of $\mathrm{PM}_{2.5}$ in India and found that north has $3.3 \mu \mathrm{g} / \mathrm{m}^{3}$ and, east, west, and south India has, respectively, $3.3,3.7,2.3$, and $1.6 \mu \mathrm{g} / \mathrm{m}^{3}$. Moreover, being a developing country, India has seen extensive urbanization; as a result, pollution is a direct outcome of urbanization and its related phenomena. The COVID-19 pandemic driven lockdown has changed the air quality in India. During the lockdown period, the concentration of particulate matter in all Indian cities decreased. This is mainly contributed due to the less number of motor vehicles and roadside food-vendors who use coal cook stoves which are the important sources of pollutant in Indian cities. In a recent research outcome, i.e., Sharma et al. 2020 found that there is a $43 \%$ decrease in $\mathrm{PM}_{2.5}$ and $18 \%$ decrease in $\mathrm{NO}_{2}$ in India during the first half of lockdown stage compared to earlier years. Mahato et al. 2020 established that during the lockdown period, the greatest reduction in $\mathrm{PM}_{10}$ and $\mathrm{PM}_{2.5}$ intensities was found to be greater than $50 \%$. They also observed that the air quality is improved by $40 \%$ to $50 \%$ during the four days of the lockdown. Moreover, Huang et al. 2020 found that $\mathrm{NO}_{2}$ in the atmosphere over the eastern parts of China had decreased by approximately $65 \%$ in comparison with the previous year.

However, it has been noticed that COVID-19-affected patients have similar symptoms to other affected illnesses, e.g. cough, fever, respiratory disorder, and pneumonia. It has been found that the growth of other Coronavirus has significant relation to increase or decrease in temperature in the region. Bashir et al. 2020b analyzed the COVID-19 outbreak in the New York City with daily temperature, humidity, wind speed, and air quality; and according to their finding ingrowth of COVID-19. The affected people has positive correlation with minimum temperature and air quality. Dalziel et al. 2018a found the similar results that the influenza health epidemic follows a seasonal pattern of the climatic parameter; after the end of rainy and summer season's infection-related health epidemic generally followed the increasing trend. Dalziel et al. (2018a) also found that the spatial variation of humidity differentiation in the incidence of influenza in the USA. The seasonal fluctuation of humidity leads to the seasonal outbreak of influenza, especially in winter. Tan et al. 2005 analyzed the relationship between SARS outbreak and daily temperature in the major cities of China, and they found that $16{ }^{\circ} \mathrm{C}-$ $28{ }^{\circ} \mathrm{C}$ was the suitable condition for the growth for SARS virus. A sharp decrease in average temperature or towards cold weather leads to an increase or outbreak of SARS virus to affect patients. Therefore, it has the high probability to other SARS group virus which would follow the same kind of spread in dynamically related to temperature and humidity. Moreover, the weather phenomena have a close relationship with the human immune system. However, meteorological parameters such as wind speed and direction also affect the increase and transition of transferable syndromes (Ma et al. 2020). In recent work, Ahmadi et al. 2020 found that the sensitivity of COVID-19 epidemic in Iran is associated with the wind speed, humidity, solar radiation, and population density. The authors also revealed that suitable climatic condition, particularly humidity in Tehran and Mazandaran provinces, increase the virus-affected populations compared to the rest of Iran. Incidentally, Van Doremalen et al. 2020 found that SARS virus can remain active for three hours on aerosol; thereby there is a high chance of transmitting the virus with the direction of wind flow. Similarly, Chen et al. 2020 found that the climatic model with relative humidity, wind speed and temperature were highly associated with COVID-19 pandemic. Further, Contini and Costabile 2020 stated that the concentration of $\mathrm{PM}_{2.5}$ and $\mathrm{PM}_{10}$ in the air with biological, physical and chemical analysis could explain the observed mortality in various parts of the World. Melin et al. 2020a, b used the Multiple Ensemble Neural Network Models with Fuzzy Response Aggregation in Mexico City for prediction of the trend of COVID-19 time series. Here in the validation data set, the simulations of several ensemble neural network models with fuzzy response integration demonstrate excellent predicted results. The prediction errors of numerous ensemble neural networks are, in fact, substantially smaller than those of typical monolithic neural networks, demonstrating the benefits of the suggested technique (Melin et al. 2020a).Sun and Wang 2020 simulated a COVID-19 outbreak caused by a single imported patient who was not subjected to rigorous isolation. The lessons learned from the newly identified cases in Heilongjiang province after April 9 should be noted since they are pharmacologically linked to this "imported escaper." They also suggested that rigorous precautions such as isolation, house quarantine, and centralized quarantine be reinstated, particularly in Haerbin City, Heilongjiang Province, to reduce the possibility of a subsequent epidemic. Castillo and Melin 2020 used "hybrid approach combining the fractal dimension and fuzzy logic" for efficient and effective prediction of COVID-19 data series. Castillo and Melin 2021 provide a hybrid intelligent fuzzy fractal technique for countries classification made on the basis of fractal theoretical notions and fuzzy logic quantitative concepts. The fractal dimension's mathematical description allows us to assess 
the complexities of the nonlinear dynamic behavior displayed by country time-series data. Several researches have recently been published with the objective of clearer appreciation COVID-19 patterns, one of which is: identifying probable patterns utilizing a collection of X-ray medical pictures from individuals with prevalent bacteria pneumonia verified with COVID-19 illness (Apostolopoulos and Mpesiana 2020; Melin et al. 2020b). Other intriguing research is the use of dynamic statistical methods to investigate COVID-19 instances in China (Sarkodie and Owusu 2020). Several Artificial Intelligence methods are being used in healthcare to analyze data and make decisions. This indicates that AI-driven technologies can assist in spotting COVID-19 outbreaks and forecasting their type and rate of spread throughout the world (Santosh 2020).

Considering the close relationship with different climatic indicators with Coronavirus along with nationwide lockdown's impact on air quality in India, the aim of the present research is to critically explore the connection between COVID-19-imposed lockdown and air quality across India during the pre-lockdown and lockdown periods. In this study apart from the improving air quality in COVID-19 pandemic-induced lockdown, we clearly demonstrated that the climatic variables are not extreme indicators for spreading of SARS COVID-19 virus in throughout the country. Some of the studies indicate that the decreasing air temperature is most favorable for spreading the COVID-19, but our study is totally against this approach. Apart from this, our aims in the study are to scientifically analyze COVID-19 pandemic-enforced nationwide lockdown and its relations to improved air quality across Indian cities. Besides, relationship between climate variables and daily new affected cases of Coronavirus and mortality in India during the lockdown period has also been examined. The present would have huge impact on post-pandemic crisis management of air quality, especially for megacities. The policymakers would have the opportunities to redesign the existing air quality regulatory mechanism.

\section{Study area}

The present study has focused in India; due to the huge variations of latitude $\left(8^{\circ} 4^{\prime} \mathrm{N}\right.$ to $\left.37^{\circ} 6^{\prime} \mathrm{N}\right)$, longitude $\left(68^{\circ} 7^{\prime}\right.$ $\mathrm{E}$ to $97^{\circ} 25^{\prime} \mathrm{E}$ ), and varying physiography, India's climate has a broad variety of weather conditions. The climate of India differs from tropical to subtropical humid, with most of the area's average temperature varying from 10 to $40{ }^{\circ} \mathrm{C}$ throughout the year (Pal et al. 2021a). The rainfall of the country varies about 100 to $150 \mathrm{~cm}$, and the country receives the maximum amount of rain during the monsoon season. It is well known fact that subtropical climatic conditions are also responsible for different types of diseases.

Moreover, India has 1.3 billion populations and $31.16 \%$ lives in fifty-three urban agglomerations spreading across the country, whereas the rest of the population $(68.16 \%)$ lives in the rural areas (Census of India 2011). In the recent decade, India has been experienced a positive increase in urbanization and economic growth (Gurjar et al. 2016), which combinedly make the country one of the largest greenhouse gas emitters; therefore, people are facing air pollution-induced problems in everyday life. Pant et al. 2020 mentioned that air quality always remains as significant environmental and health hazard problems in Indian megacities.

In addition, being a highly populated developing country, the country's health infrastructure does not have that much capacity to facilitate this huge population, whereas India suffers from poverty and a large number of families without access to basic health care services, which hinders people's health condition. The poor infrastructures lack of medicine, beds, and limited resources are common phenomena in the government-aided hospitals throughout the nation. On the other hand, private hospitals have better infrastructure that is too expensive and almost inaccessible for a low-income group of poor families. According to WHO's (WHO) guidelines, doctor population ratio should be 1:1000 but in India, it is 1:1457. Therefore, the number of doctors is far less than that is required in India. As a result of this, India is suffering to overcome the new challenges in medical and health sciences. Figure 1 shows the map of the study area with point location of data sources.

\section{Materials and methods}

\subsection{Analytical neural network (ANN)}

The ANN is a machine learning technique, connectionist system motivated by the research of biological neurons (Hewitson and Crane 1994; Levine et al. 1996). A selflearning method employs the ANN model to self-analyze the associations among multi-source data (such as combines of qualitative and quantitative information) and to determine the region more likely to trigger air quality index under certain predetermined geo-environmental circumstances. Furthermore, this method may create links to linear or nonlinear projection methods to a satisfactory precision (Licznar and Nearing 2003). ANN's are commonly used in their capability to model the dynamic process and identify the trends in science and technological problems (Jain et al. 1996; Cracknell and Reading 2014). 


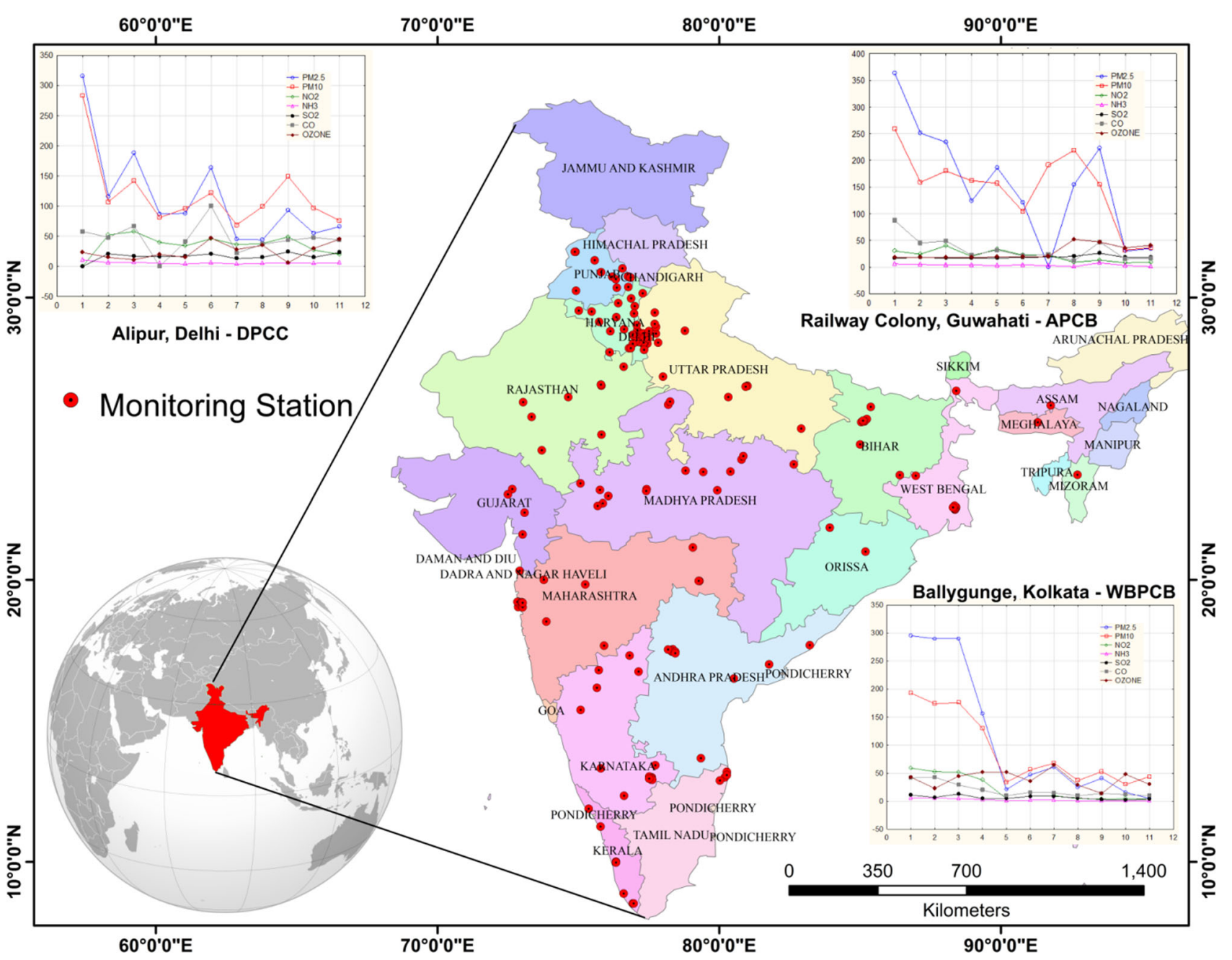

Fig. 1 Map of the study area with point location of data sources

An ANN method was constructed with considering different air quality parameters as input or covariates, and air quality index (AQI) observed dependent factors. Here, a multilayer perceptron neural network classifier has been developed using the covariates referred, e.g., $\mathrm{PM}_{2.5}(\mu \mathrm{g} /$ $\left.\mathrm{m}^{3}\right), \mathrm{PM}_{10}\left(\mu \mathrm{g} / \mathrm{m}^{3}\right), \mathrm{NO}_{2}\left(\mu \mathrm{g} / \mathrm{m}^{3}\right), \mathrm{NH}_{3}\left(\mu \mathrm{g} / \mathrm{m}^{3}\right), \mathrm{SO}_{2}(\mu \mathrm{g} /$ $\left.\mathrm{m}^{3}\right), \mathrm{CO}\left(\mathrm{mg} / \mathrm{m}^{3}\right)$, and Ozone $\left(\mu \mathrm{g} / \mathrm{m}^{3}\right)$ were considered. Hyperbolic tangent was considered for the development of the model for hidden layer initialization, and identity function was considered for the activation of the output layer. Hyperbolic tangent function takes real-valued arguments of inputs $\left(x_{1}, x_{2}, \ldots, x_{n}\right)$ and transforms them to the range $(-1,1)$ through Eq. 1 .

$f(x)=\tanh (x)=\frac{e^{x}-e^{-x}}{e^{x}+e^{-x}}$

The identity function is a linear function (Eq. 2) that obtains real-valued arguments of hidden layer and precedes them unaffected.

$f(x)=x$
There is also a supplementary neuron component, named $w_{0}$, identified as the bias that can be taken as a synapse connected with an input $A q f_{0}=-1$. The output of the neuron $A q I_{n}$ (air quality index) is supported on the creation among input vector $A q f\left(A q f_{0}, x_{1}, x_{2}, \ldots, x_{n}\right)$ and vector $w\left(w_{0}, w_{1}, w_{2}, \ldots, w_{\mathrm{n}}\right)$ composed of synapses, with the bias $\left(w_{0}\right)$, The following equations (Eqs. 3 and 4) were considered to make the $A N N$ method

$A q f \times w=\sum_{n=0}^{i} A q f_{n} \times w_{n}$

where $A q f$ are the components of air quality $\left(A q f_{\mathrm{n}}\right.$ $\left.=A q f_{0} \ldots A q f_{i}\right)$ and $w$ is the synaptic influence allocated for individual $A q f\left(w_{n}=w_{0} \ldots w_{i}\right)$.

$A q I_{n}=\varphi(A q f \times w)$

where $\varphi$ is the establishment role value and $A q I_{n}$ is the air quality index. 
Basically ANN is now one of the most useful tools that can be used to model complex patterns, to understand relative contribution of input variables on prediction and decision making. Obviously it is well known fact that taken air quality pollutant parameters $\left(\mathrm{PM}_{10}, \mathrm{PM}_{2.5}, \mathrm{CO}, \mathrm{NO}_{2}\right.$, $\mathrm{SO}_{2}, \mathrm{NH}_{3}$ and $\mathrm{O}_{3}$ ) how contribute in AQI calculation. But here we identified rationalized importance of them.

\subsection{Air quality index (AQI)}

According to the Millennium Development Goals, sustainable management is essential for a nation to progress under crucial conditions. As a measure, AQI records pollutants from the monitoring station in the surrounding air. AQI makes awareness on the public by providing information about the risk of daily pollution level and on the other hands helps to take immediate measure for this impact on the environment (Ghorani-Azam et al. 2016). It represents the consistency of the air using color schemes and graphics and graded as good, satisfactory, moderate, poor, very poor, and severe. Maximum air pollution and related diseases are indicated by the high value of AQI. Traditional AQI assessment based on individual pollutants to the norm utilizing the effective aggregation technique removes complexity, eclipse, and stiffness (Swamee and Tyagi 1999). Sharma et al. 2020 stated that AQI used maximum sub-indices using such five pollutants $\left(\mathrm{PM}_{10}\right.$, $\mathrm{PM}_{2.5}, \mathrm{SO}_{2}, \mathrm{NO}_{2}$, and $\mathrm{CO}$ ). The National Ambient Air Quality Monitoring Programme includes seven new parameters such as $\mathrm{PM}_{2.5}$, ozone $\left(\mathrm{O}_{3}\right)$, ammonia $\left(\mathrm{NH}_{3}\right)$, benzene $\left(\mathrm{C}_{6} \mathrm{H}_{6}\right)$, benzo (a), pyrene $(\mathrm{BaP})$, arsenic (As) and nickel (Ni). And rests of parameters are sulfur dioxide $\left(\mathrm{SO}_{2}\right)$, nitrogen dioxide $\left(\mathrm{NO}_{2}\right)$, particulate matter size less than 10 microns $\left(\mathrm{PM}_{10}\right)$, lead $(\mathrm{Pb})$, and carbon monoxide (CO), respectively. Three of the twelve parameters have an annual standard (annual avg.), six have an annual standard with a short term (annual 330 avg./24 h), and $\mathrm{O}_{3}, \mathrm{CO}$ alone has a short period $(1 \mathrm{~h} / 8 \mathrm{~h} / 24 \mathrm{~h})$. The current research work has aimed by presenting an integrated index of analyzing on seven pollutants $\left(\mathrm{PM}_{2.5}, \mathrm{PM}_{10}, \mathrm{NO}_{2}, \mathrm{NH}_{3}, \mathrm{SO}_{2}\right.$, $\mathrm{CO}$, and $\mathrm{O}_{3}$ ) individually in the lockdown period compared to pre-lockdown period and also indicate future condition depending on this trend.

For estimating AQI, an established method by the Central Pollution Control Board (CPCB), Govt. of India, has been followed throughout the study. The AQI has been estimated by considering the major pollutants $\left(\mathrm{PM}_{2.5}\right.$, $\mathrm{PM}_{10}, \mathrm{NO}_{2}, \mathrm{NH}_{3}, \mathrm{SO}_{2}, \mathrm{CO}$, and $\mathrm{O}_{3}$ ). All monitoring stations across India and its recorded pollutant have been considered in the present study. PM stands for particulate matter (also called particle pollution): the term for a combination of solid and liquid particles present in the air. Several molecules, like dust, dirt, soot, or smoke, are large or dark enough to be seen with the human eye. Some are so tiny that only an electron microscope can identify them. The particles in $\mathrm{PM}_{10}$ are tiny enough to enter the throat and lungs. High amounts of $\mathrm{PM}_{10}$ can cause coughing, runny noses, and stinging eyes. When $\mathrm{PM}_{10}$ levels are high, those with heart or lung problems may have greater symptoms. Wheezing, chest tightness, and trouble breathing are some of the symptoms. $\mathrm{PM}_{2.5}$ is a kind of tiny inhalable particle having a diameter of $2.5 \mu \mathrm{m}$ or less. Such particles can be made up of a lot of various chemicals and available in a multitude of sizes and forms. Carbon monoxide (CO) is a combustible gas that is colorless, odorless, and tasteless. It is somewhat less dense than air. One carbon atom and one oxygen atom make up carbon monoxide. It is the oxocarbon family's most basic chemical. The most frequent source of carbon monoxide is thermal combustion, although there are other biological and environmental sources that produce and release substantial amounts of carbon monoxide. Carbon monoxide is used in a variety of industrial processes, including synthetic chemical production and metallurgy, but it is also a contaminant in the air caused by industrial operations. Nitrogen dioxide $\left(\mathrm{NO}_{2}\right)$ is a reactive gas that belongs to the group of gases considered as nitrogen oxides $\left(\mathrm{NO}_{\mathrm{x}}\right)$. Nitrous acid and nitric acid are two other nitrogen oxides. $\mathrm{NO}_{2}$ is being used as the attribute for the wider community of nitrogen oxides. $\mathrm{NO}_{2}$ principally receives in the air from of the fuel combustion. $\mathrm{NO}_{2}$ constructs from emissions from cars, trucks and buses, power stations, and off-road materials. Ammonia $\left(\mathrm{NH}_{3}\right)$ is an amidase inhibitors and neurotoxic that is made up of a single nitrogen atom covalently linked to three hydrogen atoms. Microbial activities and the decomposition of organic materials create it both artificially and naturally. Ammonia is a chemical that is utilized in a wide range of industrial applications, as well as as a fertilizer and a refrigerant. Ozone $\left(\mathrm{O}_{3}\right)$ in the air we breathe may be harmful to our health, particularly on hot, bright days when ozone levels can approach dangerously high levels. Even modest quantities of ozone can be harmful to one's health.

There are two steps to calculate AQI, i.e. the first one is to formulate the sub-indices and the second one is the amalgamation of sub-indices to acquire AQI.

Further the sub-index functions were used to formulate sub-indices for $n$ numbers of pollutants; mathematically it is expressed as

$I_{i}=f\left(X_{i}\right), i=1,2, \ldots, n$.

Amalgamation of sub-indices to acquire AQI is done using some numerical function, i.e., expressed as 
$I=F\left(I_{1}, I_{2}, \ldots, I_{n}\right)$

The relationship between sub-index $\left(I_{i}\right)$ and pollutants concentration $\left(X_{i}\right)$ is expressed as

$I=\alpha X+\beta$

where $\alpha$ indicates slope of the line and $\beta$ indicates intercept at $X=0$.

On the other hand, sub-indices $\left(I_{i}\right)$ for a identified pollutant attentiveness $\left(C_{\mathrm{p}}\right)$ are expressed as,

$I_{i}=\left[\left\{\left(I_{\mathrm{HI}}-I_{\mathrm{LO}}\right) /\left(B_{\mathrm{HI}}-B_{\mathrm{LO}}\right)\right\} \times\left(C_{\mathrm{P}}-B_{\mathrm{LO}}\right)\right]+I_{\mathrm{LO}}$

here $B_{\mathrm{HI}}$ indicates cutoff point attentiveness $\geq$ known attentiveness; $B_{\mathrm{LO}}$ indicates cutoff point attentiveness $\leq$ known attentiveness; $I_{\mathrm{HI}}$ means AQI value equal to $B_{\mathrm{HI}} ; I_{\mathrm{LO}}$ means AQI value equivalent to $B_{\mathrm{LO}}$ and $C \mathrm{p}$ specifies pollutant concentrations.

Thereafter, weighted additive value was calculated to amalgamation of sub-indices and is expressed as

$I=$ Aggregated Index $=\sum W_{i} I_{i}($ for $I=1, \ldots, n)$

where $\sum W_{i}$ equals $1, I_{i}$ indicates sub-index of pollutant $\mathrm{I}, \mathrm{n}$ indicates amount of different pollutants, and $W_{i}$ means influence of the pollutant.

Minimum or maximum operator form is expressed as (Ott 1978):

$I=$ Minimum or $\operatorname{Maximim}\left(I_{1}, I_{2}, I_{3}, \ldots n\right)$.

The scientific rationalize behind the correlation is as the COVID-19 cases followed the normal probability distribution, so the nonparametric correlation method is suitable to understand the covid19 cases with others environmental parameters like climate. Others scientific study also established that climate is an important variable of COVID-19 infection.

\subsection{Kendall and Spearman rank test}

We have conduct the probability distribution of various climatic condition and definite cases of COVID-19 with the help of Kendall test and Spearman correlation. This nonparametric method has also been applied because the distribution has followed the normal probability distribution (Taylor 1987). Finally, Fig. 2 shows the generalized methodology flowchart to demonstrate the brief theme of this research.

The Mann-Kendall test base described as follows on the test statistics $S$

$S=\sum_{i=1}^{n-1} \sum_{j=i+1}^{n} \operatorname{sgn}\left(x_{j}-x_{i}\right)$

where $x_{j}$ is the continuous data value, $\mathrm{n}$ is the data sets length, and $\operatorname{sgn}(\theta) \begin{cases}1 & \text { if } \theta>0 \\ 0 & \text { if } \theta=0 . \\ -1 & \text { if } \theta<0\end{cases}$

Mann (1945) and Kendall (1975) have reported that statistics $S$, with the mean and variance as followed, is distributed essentially normally when $n \geq 8$

$E(S)=0$

$V(S)=\frac{n(n-1)(2 n+5)-\sum_{i=0}^{n} t_{i} i(i-1)(2 i+5)}{18}$

where $t_{i}$ is the degree number of relations $i$. Standardized statistics of tests $z$ are determined by

$Z_{\mathrm{MK}}= \begin{cases}\frac{S-1}{\sqrt{\operatorname{Var}(S)}} & S>0 \\ 0 & S=0 . \\ \frac{S+1}{\sqrt{\operatorname{Var}(S)}} & S<0\end{cases}$

The standard normal distribution with a mean of zero and variance of one is followed by the normalized MK statistics $Z$.

\section{Results}

\subsection{Spatial mapping of major pollutants during pre-lockdown and lockdown}

The Lockdown Policy was introduced by the Indian Government in order to mitigate and monitor the COVID19 pandemic. It was a collective decision to maintain a social distancing policy and to avoid mass gathering. Along with the above strategy, strict measures have been taken to put an end to transport systems (road, rail, air) and to the closure of major industries. The entire shutdown of traffic flow, industries, hotels, stores, and government offices resulted in a massive change in air pollution, especially among important prominent components including $\mathrm{PM}_{10}$, $\mathrm{PM}_{2.5}, \mathrm{CO}, \mathrm{NO}_{2}, \mathrm{SO}_{2}, \mathrm{NH}_{3}$, and $\mathrm{O}_{3}$ (Fig. 3). This can be clearly seen from the spatial distribution of the accumulated $\mathrm{PM}_{10}, \mathrm{PM}_{2.5}, \mathrm{CO}, \mathrm{NO}_{2}, \mathrm{SO}_{2}$, and $\mathrm{NH}_{3}$ contaminants at various pre-lockdown, lockdown, and predicted postlockdown periods (Fig. 3). Particularly, the amounts of the pollutants only decreased below the permissible limit within one week of the shutdown (March 24, 2020 to March 31, 2020), whereas the absorption of $\mathrm{O}_{3}$ increases in manufacturing and transport conquered region. Later, the central government has given a limited relaxation (April 14, 2020) of the lockdown measures of COVID-19 for the necessary vehicles and human activities beyond the red zone, with a marginal effect on air pollutants. Owing to COVID-19 lockdown steps, the emissions declined 


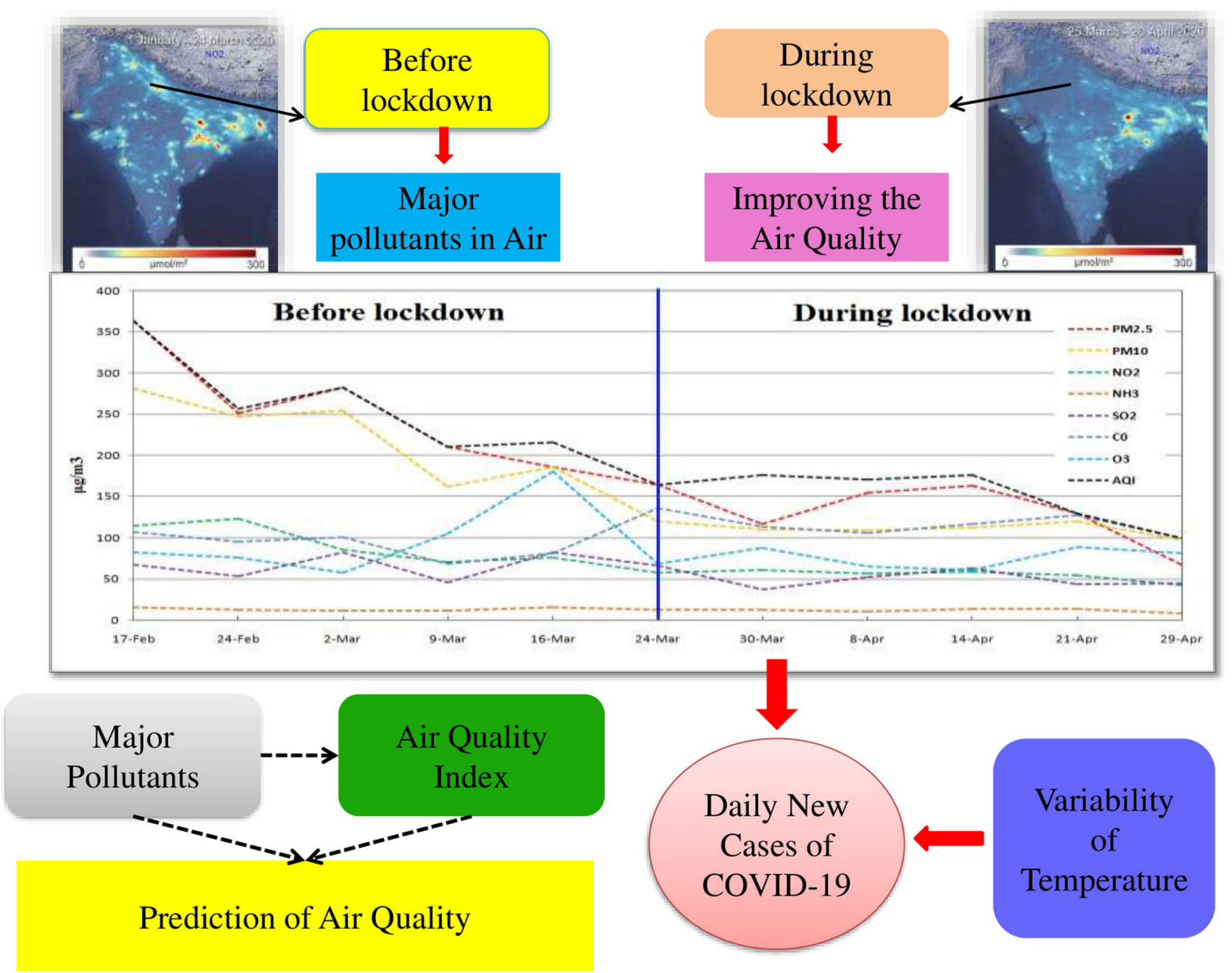

Fig. 2 Methodology flowchart

dramatically in the vehicular traffic and the shutdown of factories, restaurants, shops, government offices, and several other human-induced activities (Fig. 3).

It was observed that air quality is improved drastically during the pre-lockdown period (24th March, 2020) of the COVID-19-extended lockdown phase (3rd May, 2020) and air quality is deteriorated slightly after the government gave a minor relaxation (April 14, 2020) to the necessary vehicles and other human activities beyond the red zone. On average, there is a significant improvement in air quality $(-26.99 \%$ with the net reduction of -39.16$)$ throughout three weeks lockdown durations (March 24, 2020 , to April 14, 2020) relative to the standard air quality over three weeks pre-lockdown period (Fig. 3h). During the predicted post-lockdown phase (after 3rd May, 2020), air quality dropped dramatically; this is like at the value similar to the start of the lockdown period (March 24, 2020).

\subsection{Changes in major pollutants concentration during pre-lockdown, lockdown, and post- lockdown}

The change in the intentness of major air pollutants is very clear from the predicted outcomes that during the prelockdown period of COVID-19 (before March 24, 2020) the country witnessed massive air pollutants as in the previous months or years. However, after the lockdown (March 24, 2020), a major reduction in pollutants was observed throughout the country as a result of the COVID19 pandemic (Fig. 4). In particular, significant decreases in quantity of pollutants such as $\mathrm{PM}_{10}, \mathrm{PM}_{2.5}, \mathrm{CO}, \mathrm{NO}_{2}, \mathrm{SO}_{2}$ and $\mathrm{NH}_{3}$ have been estimated during the lockdown period (Fig. 4). The average assemblies of ambient air pollutants such as $\mathrm{PM}_{10}$ and PM2.5 have reduced by $-40.84 \%$ and $-45.38 \%$, respectively. The decline rate of $\mathrm{PM}_{10}$ and $\mathrm{PM}_{2.5}$ is directly linked with automobile emissions, industrial dust, and cooking smoke or to complicated 
reactions with chemicals such as $\mathrm{SO}_{2}$ and NO. Forest fires, wood burners, agricultural burning, industrial smoke, and dust from various work sites all contributed to the decline in $\mathrm{PM}_{10}$ and $\mathrm{PM}_{2.5}$ concentrations (Majumdar et al. 2020). Other pollutants that have displayed a significant difference between pre-lockdown and lockdown are $\mathrm{CO}(-19.76 \%)$ and $\mathrm{NO}_{2}(-37.80 \%)$, whereas in $\mathrm{SO}_{2}(-33.81 \%)$ and $\mathrm{NH}_{3}(-17.06 \%)$, the decline was very low compared to the others pollutants, and there was also no strong trend of regression. The accumulation of $\mathrm{O}_{3}$ increases in manufacturing and transport dominated region, in particular, $>10 \%$ rise. The source of this increased in $\mathrm{O}_{3}$, particularly in industrial and transport dominated areas, is decline in $\mathrm{NO}$, which contributes to reduce in $\mathrm{O}_{3}$ consumption ( $\mathrm{NO}+\mathrm{O}_{3}=\mathrm{NO}_{2}+\mathrm{O}_{2}$ ) and causing a raise in $\mathrm{O}_{3}$ levels. According to the study, it will take at least 180 days to record the concentration of key air pollutants during the post-lockdown of the COVID-19 pandemic, such as pre-lockdown levels across the country. It is a good sign that a significant perfection in air quality might be probable if the strict accomplishment of emissions control policies such as lockdown is enforced.

\subsection{Spatial variation of $\mathrm{PM}_{10}, \mathrm{PM}_{2.5}, \mathrm{CO}, \mathrm{NO}_{2}$, $\mathrm{SO}_{2}, \mathrm{NH}_{3}$, and $\mathrm{O}_{3}$, concentrations}

In the last 5 years (2016 to 2020), we have observed the seven contaminants' 24 -h accumulation phase during the same two months span (i.e. March and April). Continuous measurements of $\mathrm{PM}_{10}, \mathrm{PM}_{2.5}, \mathrm{CO}, \mathrm{NO}_{2}, \mathrm{SO}_{2}$, and $\mathrm{NH}_{3}$ pollutants were acquired from the air quality monitoring station of India (Kamyotra and Sinha 2016). For this research, we utilized air quality monitoring data from 223 monitoring sites across India as a particular direction. According to the data, the lockdown resulted in a significant reduction in air quality across India. In contrast to $\mathrm{PM}_{10}$ and $\mathrm{PM}_{2.5}$ which have decreased dramatically $(-40.84 \%$ and $-45.38 \%)$ during lockdown phase, $\mathrm{NO}_{2}$ and $\mathrm{CO}$ have decreased drastically $(-37.80 \%$ and $19.76 \%$ ), while pollutants such as $\mathrm{SO}_{2}$ and $\mathrm{NH}_{3}$ may have slight declination trends $(-33.81 \%$ and $-17.06 \%)$ compared to others. The maximum $\mathrm{PM}_{10}$ and $\mathrm{PM}_{2.5}$ noticed in 2019 were as high as $264.82 \mu \mathrm{g} / \mathrm{m}^{3}$ and $344.07 \mu \mathrm{g} / \mathrm{m}^{3}$, respectively. This net decreased to $-113.10 .44 \mu \mathrm{g} / \mathrm{m}^{3}$ $\left(-59.86 \%\right.$ maximum reduction) and $-57.56 \mu \mathrm{g} / \mathrm{m}^{3}$ (-45.05\% maximum reduction), respectively, in 2020 . The amount of $\mathrm{O}_{3}$ increases in manufacturing and transport dominated region. The results indicate that the accomplishment of the lockdown would lead to a significant improvement in air quality and should be placed into practice as an additional way of reducing pollution. The spatial distribution of all the pollutants except ozone are maximum in some pockets, i.e., National Capital Region
4Fig. 3 Spatial distribution of $\mathrm{PM}_{2.5}\left(\mu \mathrm{g} / \mathrm{m}^{3}\right)$ in before and during lockdown periods $(\mathbf{a})$, spatial distribution of $\mathrm{PM}_{10}\left(\mu \mathrm{g} / \mathrm{m}^{3}\right)$ in before and during lockdown periods (b), spatial distribution of $\mathrm{NO}_{2}\left(\mu \mathrm{g} / \mathrm{m}^{3}\right)$ in before and during lockdown periods (c), spatial distribution of $\mathrm{NH}_{3}$ $\left(\mu \mathrm{g} / \mathrm{m}^{3}\right)$ in before and during lockdown periods $(\mathbf{d})$, spatial distribution of $\mathrm{SO}_{2}\left(\mu \mathrm{g} / \mathrm{m}^{3}\right)$ in before and during lockdown periods (e), spatial distribution of $\mathrm{CO}\left(\mu \mathrm{g} / \mathrm{m}^{3}\right)$ in before and during lockdown periods (f), spatial distribution of ozone $\left(\mu \mathrm{g} / \mathrm{m}^{3}\right)$ in before and during lockdown periods (g), and spatial distribution of air quality index in before and during lockdown periods (h)

(NCR), Mumbai metropolitan region, Kolkata, Guahati, and its surrounding regions. Similar spatial allocation has been associated in the case of air quality index. The gradual declining tendency has been associated among pollutant materials and its resultant air quality in lockdown period.

\subsection{Correlation between pollutants in the atmosphere}

The correlation between various concentrations of air pollutants in India during the study period (i.e., from February 17, 2020, to April 29, 2020) is shown in Fig. 5. The mean daily accumulation of $\mathrm{PM}_{2.5}$ is directly linked to the average daily concentration of $\mathrm{PM}_{10}(r=0.73), \mathrm{NO}_{2}$ $(r=0.58)$, CO $(r=0.34)$ and AQI $(r=0.92)$. Similarly, the average daily concentration of $\mathrm{PM}_{10}$ is directly correlated with the maximum daily concentration of $\mathrm{PM}_{2.5}$ $(r=0.73), \mathrm{NO}_{2}(r=0.48), \mathrm{NH}_{3}(r=0.41), \mathrm{CO}(r=0.39)$ and AQI $(r=0.80)$. The mean daily accumulation of $\mathrm{NO}_{2}$ is directly linked to the average daily concentration of $\mathrm{PM}_{2.5}(r=0.58), \mathrm{PM}_{10}(r=0.48)$ and AQI $(r=0.58) . \mathrm{NH}_{3}$ by the mean daily aggregation is directly linked to the average daily concentration of $\mathrm{PM}_{10}(r=0.41)$. Similarly, the average daily aggregation of $\mathrm{SO}_{2}$ is linked with AQI $(r=0.30)$. The daily concentration of $\mathrm{CO}$ has a positive relation with $\mathrm{PM}_{2.5}(r=0.34), \mathrm{PM}_{10}(r=0.39)$ and AQI $(r=0.40)$. The daily aggregation of AQI is also directly linked to the average daily concentration of $\mathrm{PM}_{2.5}$ $(r=0.92), \quad \mathrm{PM}_{10} \quad(r=0.80), \quad \mathrm{NO}_{2} \quad(r=0.58), \quad \mathrm{SO}_{2}$ $(r=0.30)$ and $\mathrm{CO}(r=0.40)$.

\subsection{Results of ANN modelling}

After several years of experience, we got an integrated network structure with a minimum error rate for both training and testing. It used $69.1 \%$ of total data to train the network and rest $30.9 \%$ for testing the model. There were one hidden layer with 5 hidden nodes (Fig. 6) in the network structure. The Sum of Squares Error (SSE) was 1.548 for training and 1.055 for testing with a relative error of 0.012 and 0.021 , respectively. Observed values were well correlated with predicted values (Fig. 7) with a high degree 
(a)
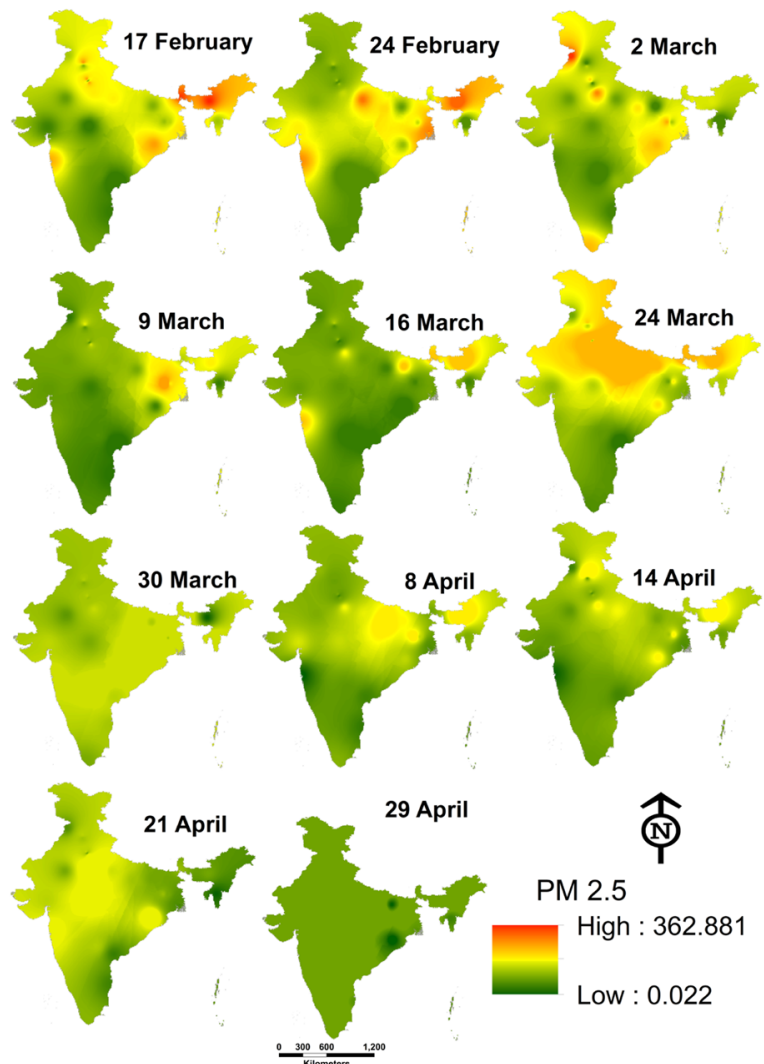

(c)
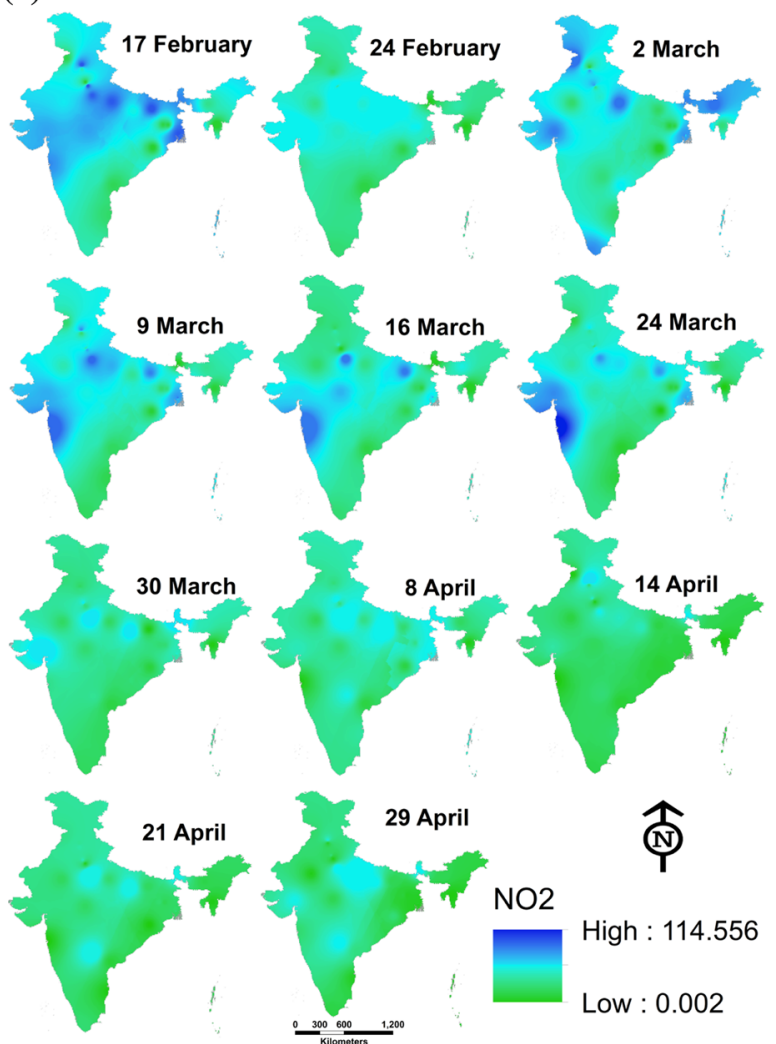

需

High : 114.556

Low : 0.002 (b)
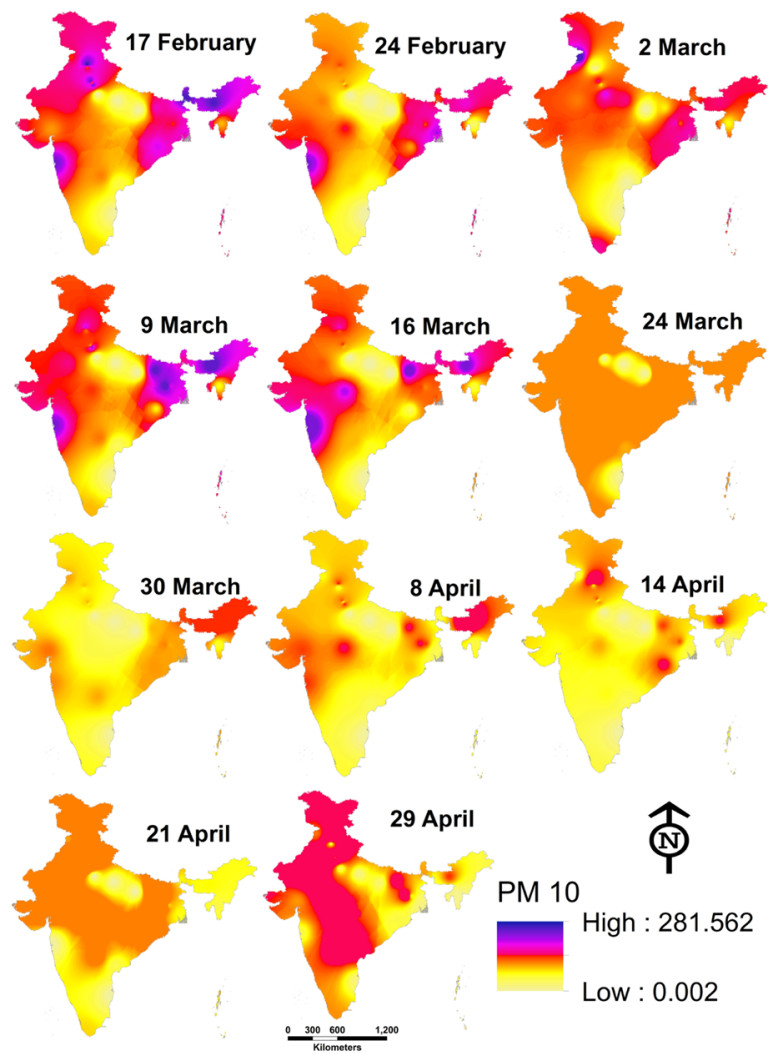

䨓

PM 10

High : 281.562

(d)
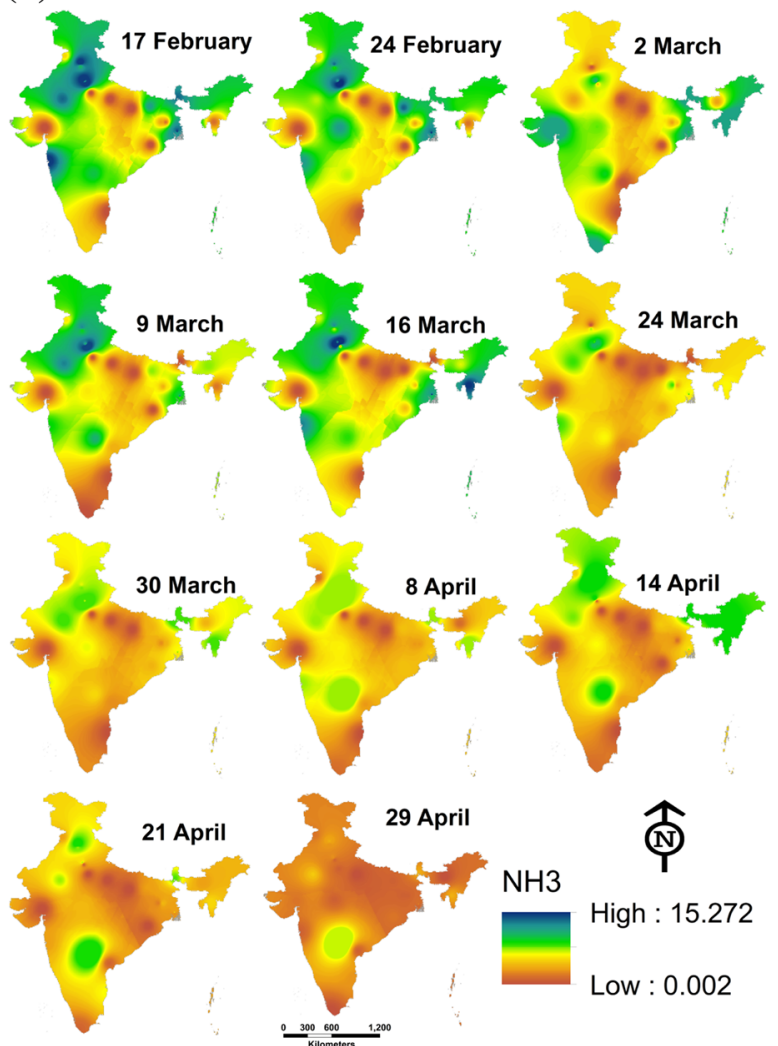

High : 15.272

Low : 0.002 
(e)
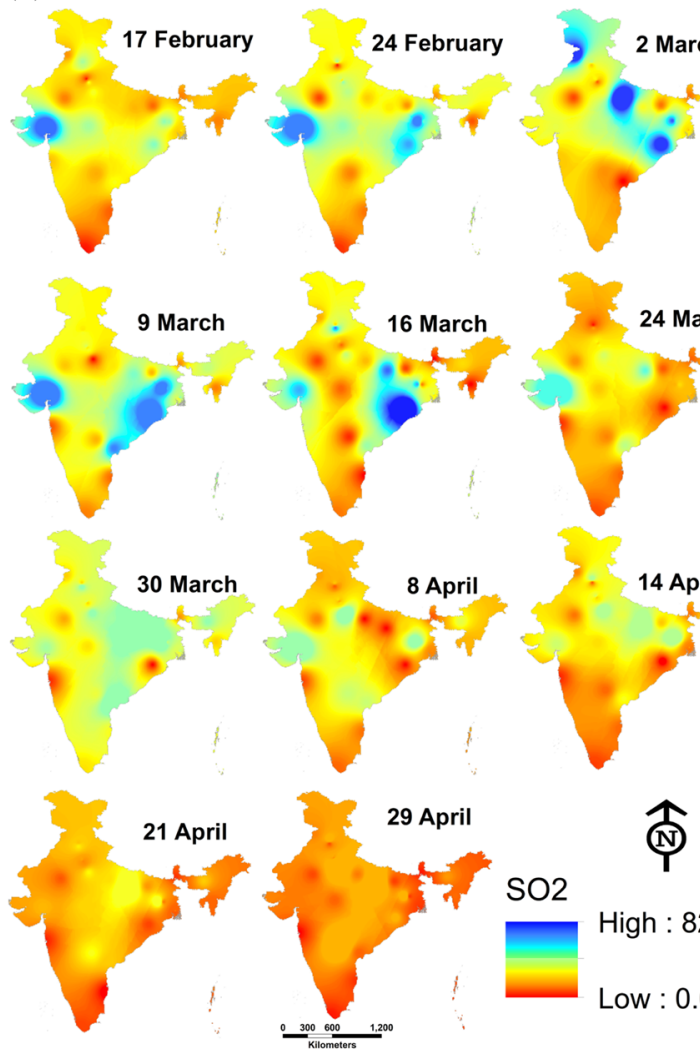

(g)
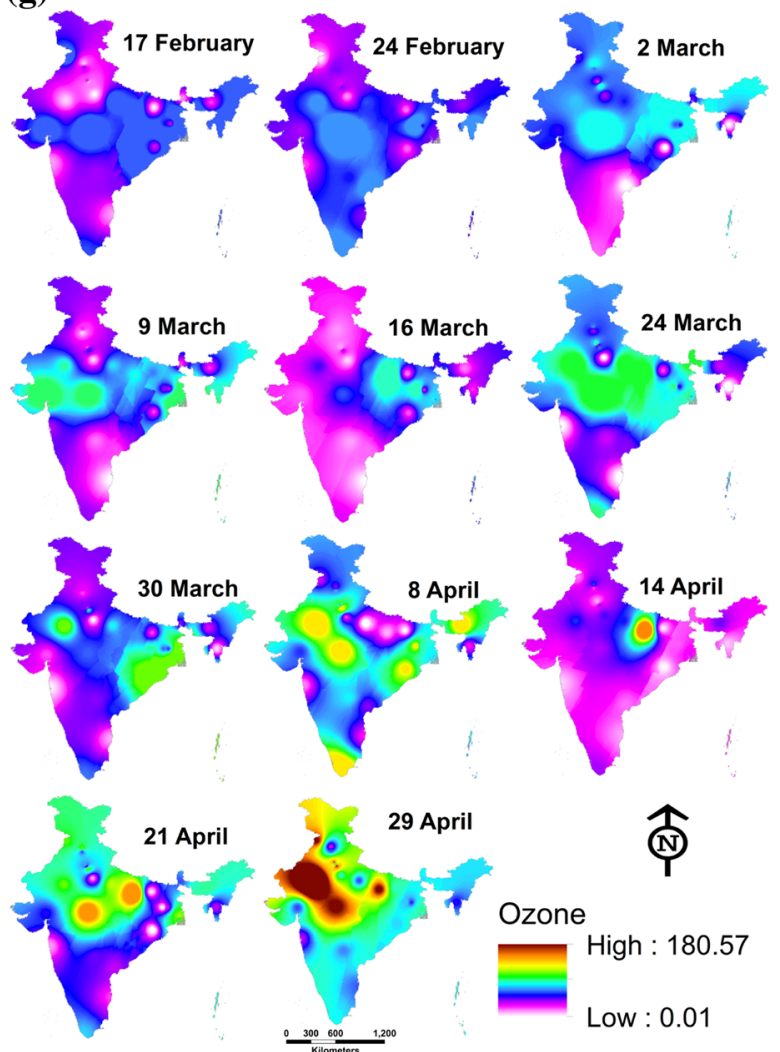

(f)
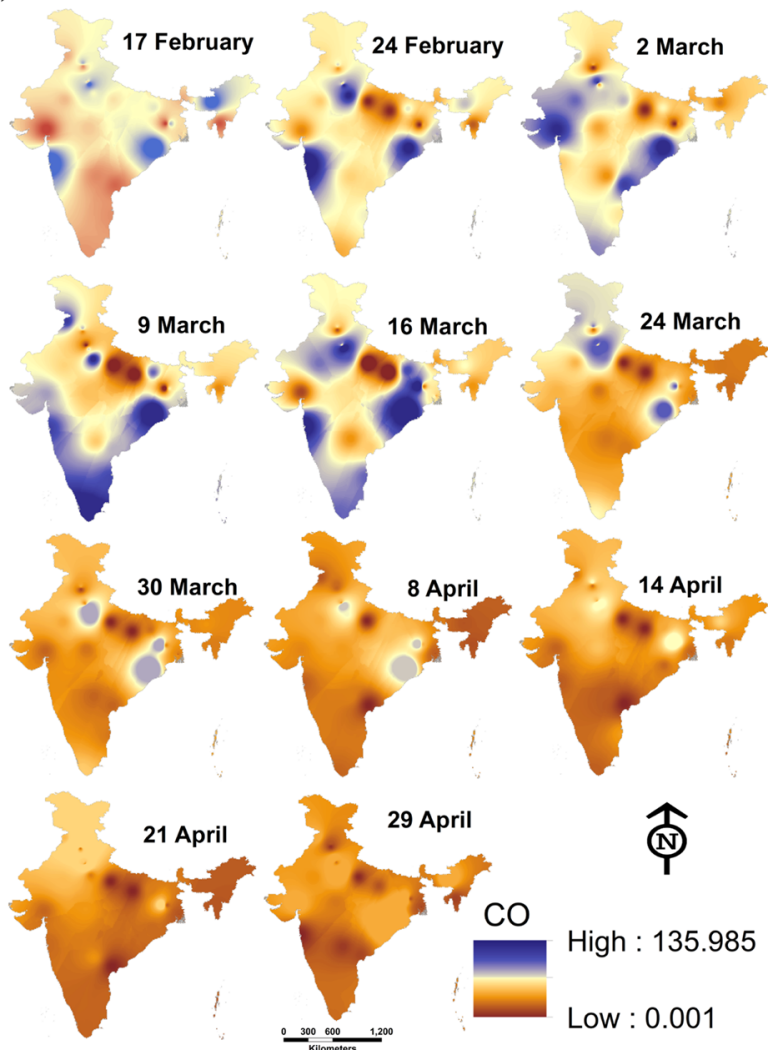

(h)
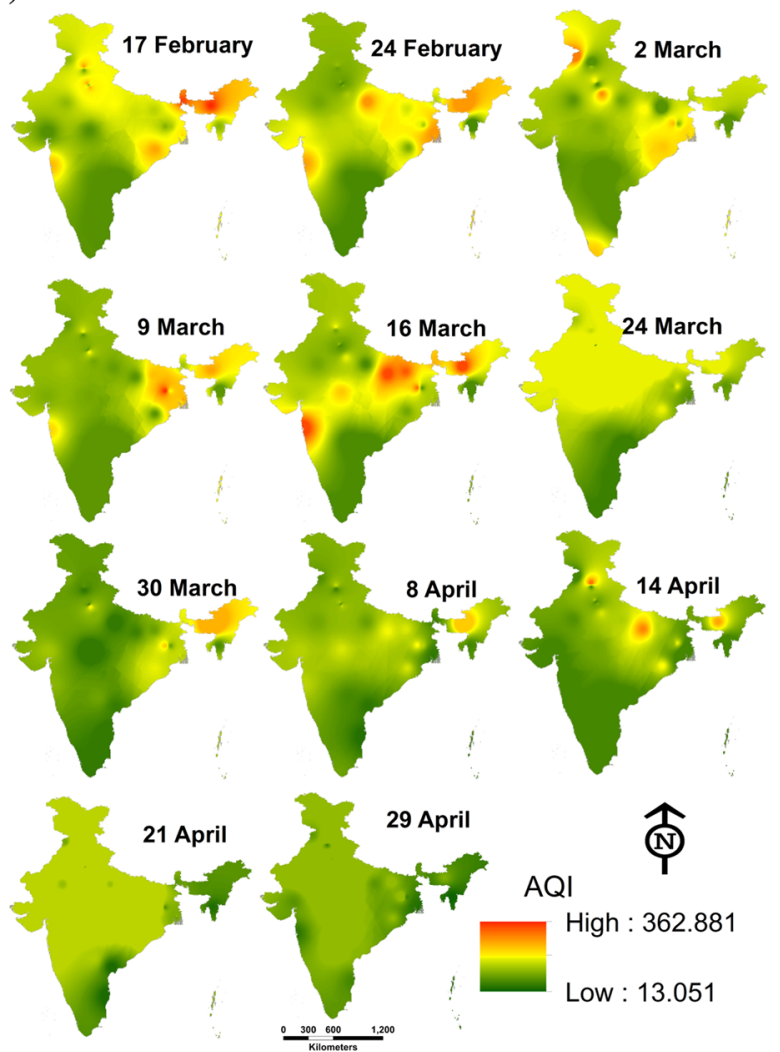

Fig. 3 continued 

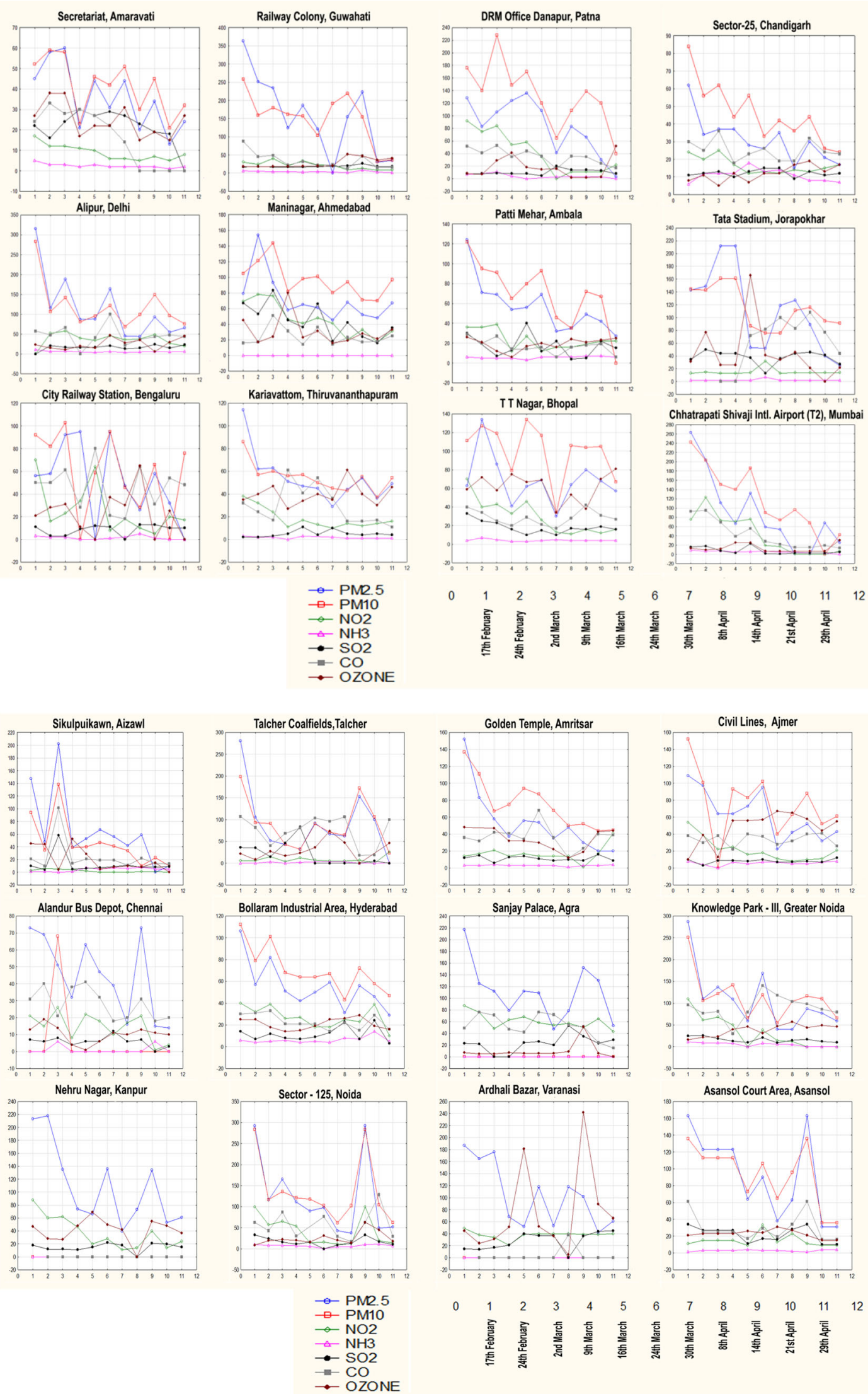

Fig. 4 Trend of major pollutants in some selected monitoring station 


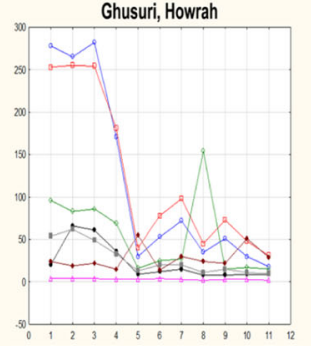

Jadavpur, Kolkata

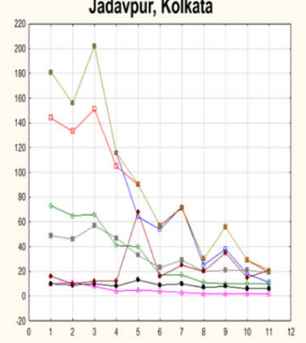

Ward-32 Bapupara, Siliguri

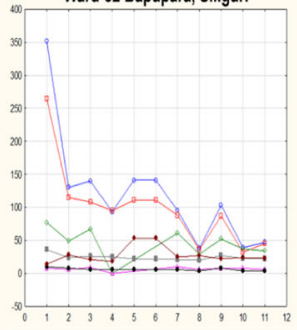

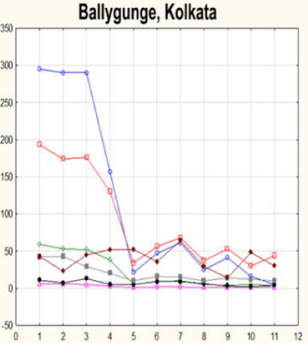

Rabindra Bharati University

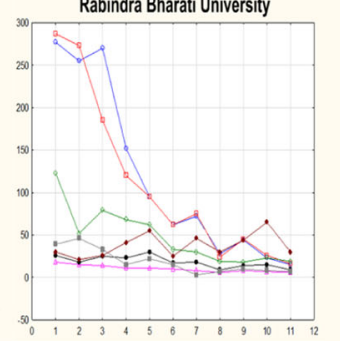

- PNR 5

$\rightarrow \mathrm{PM} 10$

$\rightarrow \mathrm{NO2}$

$\leftarrow \mathrm{NH} 3$

$\rightarrow \mathrm{SO} 2$

$-\mathrm{CO}$

$\rightarrow$ OZONE

0

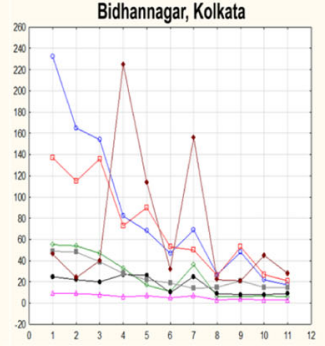

Rabindra Sarobar, Kolkata
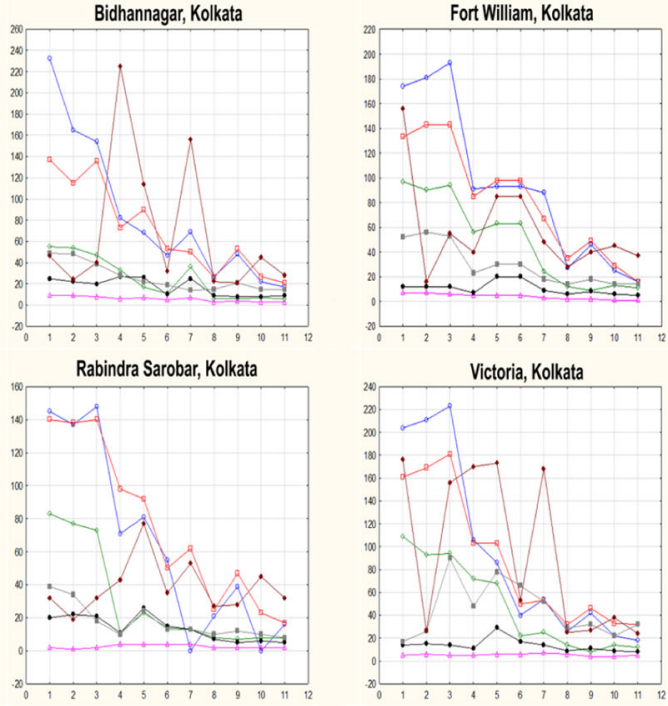

Victoria, Kolkata

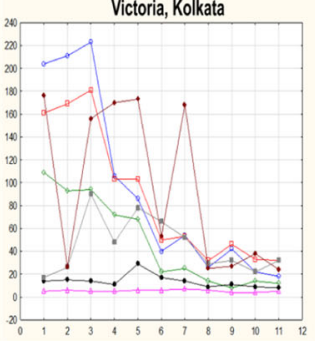

\begin{tabular}{|c|c|c|c|c|c|c|c|c|}
\hline 2 & 3 & 4 & 5 & 6 & 7 & 8 & 9 & 10 \\
\hline 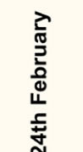 & & 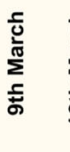 & 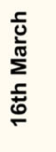 & 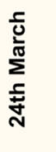 & 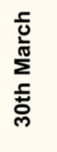 & $\begin{array}{l}\overline{\mathbf{z}} \\
\overline{4} \\
\overline{\mathbf{E}} \\
\overline{\mathbf{z}}\end{array}$ & 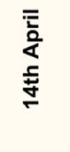 & $\frac{\vec{m}}{\stackrel{\omega}{N}}$ \\
\hline
\end{tabular}

Fig. 4 continued

of explainability $\left(R^{2}\right.$ linear $\left.=0.985\right)$. Among the predictor covariates, $\mathrm{PM}_{2.5}$ contributed most $(0.366)$ for AQI prediction, followed by $\mathrm{PM}_{10}(0.337)$. $\mathrm{NH}_{3}$ has just minimal accountability (0.029) for this result (Fig. 8). Normalized importance of input variables is given in (Fig. 8). Synaptic weights in between input variables-hidden node and hidden node-output (Table 1) are the weighing factor for prediction through Eqs. 3 and 4.

\subsection{Influence of climate indicators on mortality}

The empirical results of seven atmospheric factors are presented in Tables 2 and 3 using the Kendal and Spearman rank correlation analysis. Results indicated that the average air quality and maximum temperature are relevant for COVID-19-positive new cases (Figs. 9 and 10). The variation of temperature from high to low influences the spreading of virus in nationwide. Though India faces mortality and positive cases, but by comparison it is quite low than other non-tropical countries which has the similar range of temperature, i.e., from 3 to $17{ }^{\circ} \mathrm{C}$. In addition, according to Spearman test, average air quality and mean temperature indicate the positive case and mortality of COVID-19. The changing climate patterns for existing research have been examined for COVID-19 pandemic in highly populated countries like India. Our experiments showed that the maximum temperature and the average temperature are connected to the regional distribution of COVID-19 during the lockdown period. Shi et al. (2020); Bashir et al. (2020a) supported our outcomes, which examined at climate changes and claimed that temperature was the controlling factor behind COVID-19. Apart from this, humidity and temperature play an important role in the spreading of COVID-19 (Sajadi et al. 2020). The Wuhan incidence of COVID-19 revealed a close relation between diseases spread and weather patterns, with projections that warmer weather can control the virus (Wang et al. 2020). Dalziel et al. $2018 \mathrm{~b}$ predicted that growing magnitude of seasonal variations in specific humidity contributes to more severe pandemics. Apart from this, meteorological parameters like air quality, humidity, and wind speed also accelerated the spread of COVID-19. In fact, air temperature also leads to the spread of the virus (Chen et al. 2020). In those areas where absolute humidity varies between 3 and $9 \mathrm{~g} / \mathrm{m}^{3}$ and the atmosphere is hot in nature, the MIT community has previously confirmed 90 percent events. In this regard, Poole 2020 has also corroborated this by stating that humidity and climate indicators are associated with the 

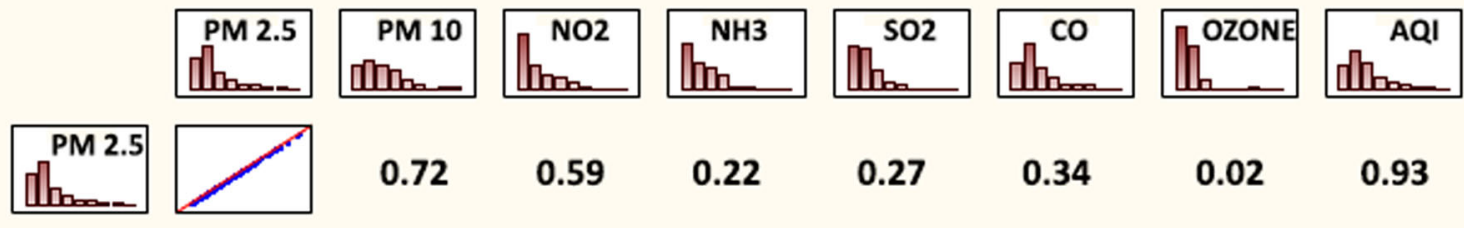

0.72

0.59

0.22

0.27

0.34

0.02

0.93
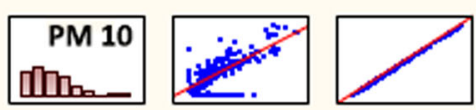

0.46

0.41

0.23

0.39

0.00

0.78
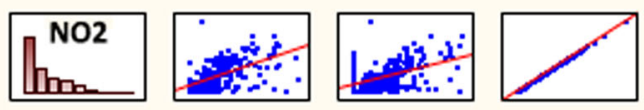

0.26

0.24

0.23

0.11

0.59
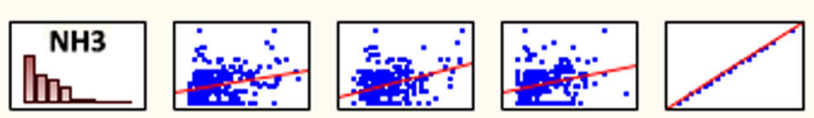

$-0.11$

0.14

$-0.01$

0.23
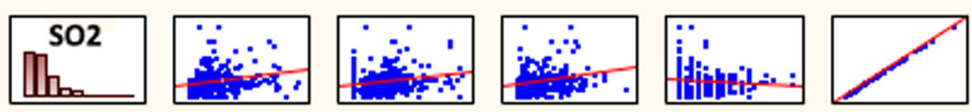

0.17

0.13

0.30
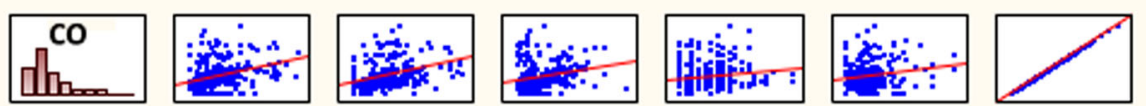

$-0.01$

0.40
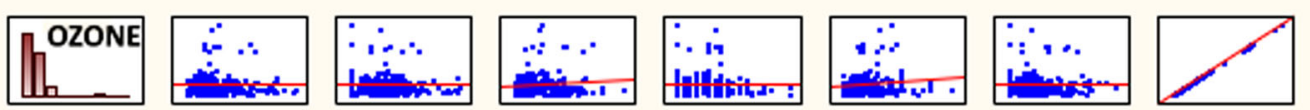

0.17
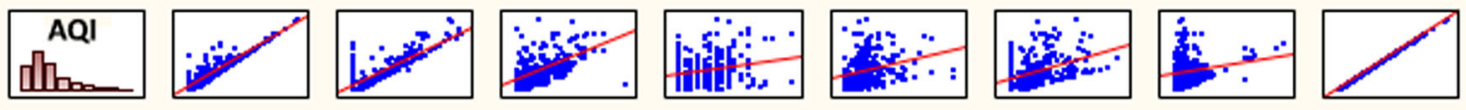

Fig. 5 Correlation of different pollutants in India during lockdown

COVID-19 spread. Therefore, it can be said that the maximum temperature and humidity have altered the mortality trend in India than American and European countries. So there are very close connection between climate indicators and the distribution of COVID-19. The average temperature was shown to have a substantial link to both mortality and case incidence (Tzampoglou and Loukidis 2020). Its impact appears to be as least as important as the speed with which the government responds. Because of its non-monotonic nature, relative humidity was shown to have a considerable but difficult to detect impact. Nonetheless, the population's age structure appeared as one of the most significant risk factors (Tzampoglou and Loukidis 2020). As a consequence, all of the researches included in this systematic review had mixed results, and none of them provided conclusive evidence that a rise in temperature lowers COVID-19 case numbers (Chin et al. 2020). Despite this, most researches show a negative connection between COVID-19 and temperature, which, when combined with in vitro investigations on the virus's stabilizing impact, suggests a negative link (Briz-Redón and Serrano-Aroca 2020). Chin et al. 2020 show that summer weather may lower COVID-19 transmission to some amount, but not enough to end the pandemic, in line with the findings of rigorous research (Yao et al. 2020; Xu et al. 2020). However, given the ambiguity of the COVID-19 data and the potential effect of the statistical and modeling methodology on the conclusions, these findings should be taken with caution.

\section{Discussion}

India ranks fifth in the world's most polluted countries and is the home to the 21 most polluted cities in the world, based on concentrations of $\mathrm{PM}_{2.5}$ and $\mathrm{PM}_{10}$. In a recent decade, numerous suggestive measures have failed to maintain the standard air quality across Indian cities. However, the scenario has changed due to COVID-19 pandemic, the environment and air quality have improved significantly. The particulate matter $\left(\mathrm{PM}_{2.5}, \mathrm{PM}_{10}\right)$ which is related to automobile emissions, industrial emissions, dust, cooking smoke are one of the most dangerous air pollutants reduced drastically from 138.85 to $75.84 \mu \mathrm{g} / \mathrm{m}^{3}$ in India. However, due to relaxation permitted after April 142020 by the government beyond the red zone has resulted in the smaller fluctuation on the prediction of selected air pollutants. As well as the spatial prediction of the AQI during pre-lockdown and lockdown period indicates a significant improvement in air quality, but the reduction of air quality was observed in the post-lockdown phase. This also indicates the chance of an increase in the air pollutants with 


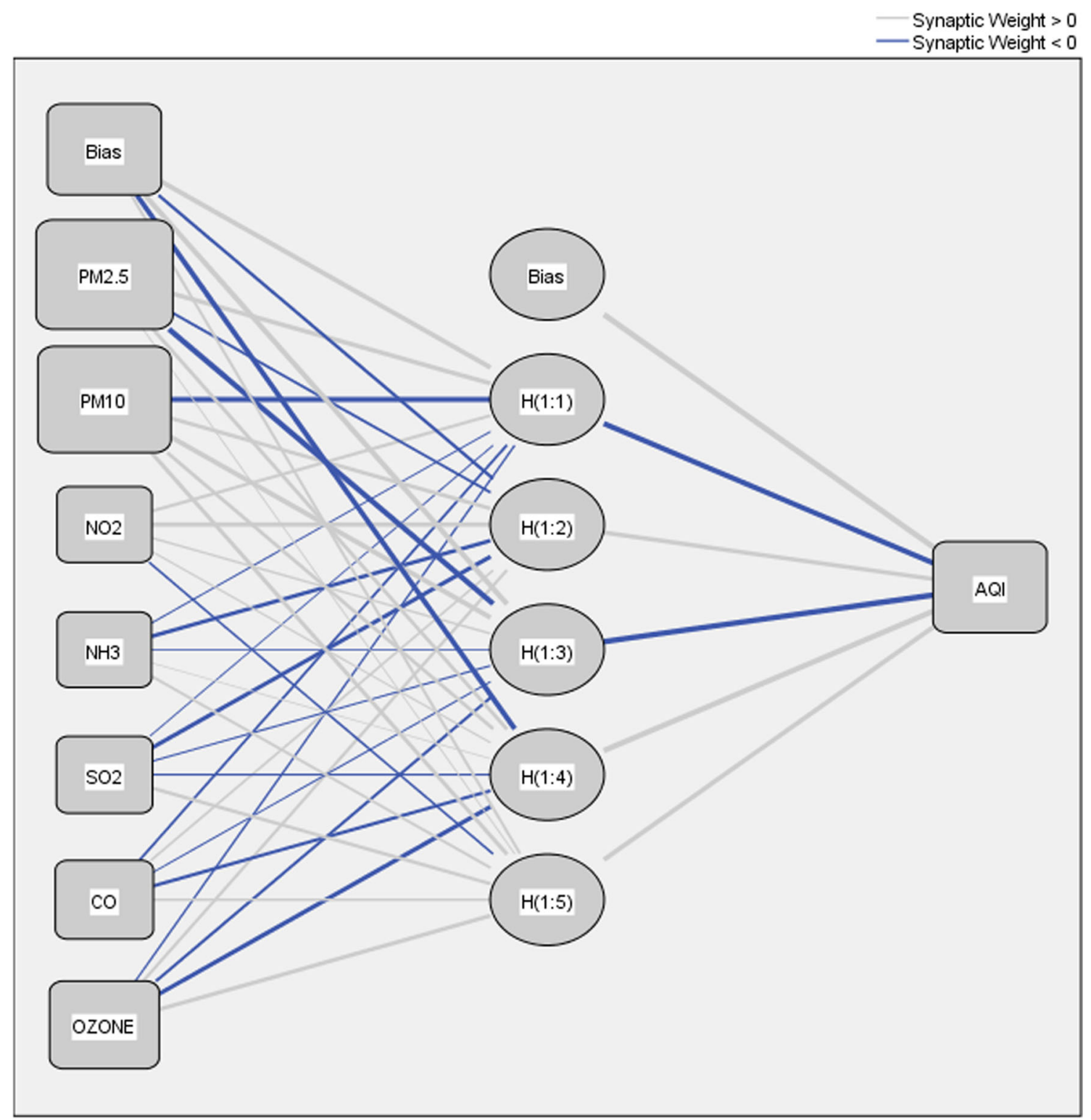

Hidden layer activation function: Hyperbolic tangent

Output layer activation function: Identity

Fig. 6 Structure of the network in ANN model

increasing relaxation in the coming days. Decreasing air pollutants due to lockdown for restricting of COVID19 community spread has been observed around the world (Huang et al. 2020).

However, the highly transmissible COVID-19 has forced the world to shutdown mode and responsible for 238,650 deaths in all over the world (WHO 2020), whereas in India at present the number of deaths is 1323 and it is going on. The nature of COVID-19 is still not known completely (Van Doremalen et al. 2020). Primary statements from WHO clearly stated there were signs of humanto-human transmission (Twitter handle of WHO, on
January 14, 2020, but after some days it was found the COVID-19 is highly transmissible from human-to-human contact. The present study indicates that the mortality rate significantly related to the maximum temperature, minimum temperature, average temperature, and air quality (Tables 2,4). The increasing daily new cases have always increased the mortality rate in India. However, the higher amount of correlation values for daily new deaths, cumulative deaths, and mortality rate were associated positively with maximum temperature and negatively with air quality. Similar results were also observed over the USA by Bashir 

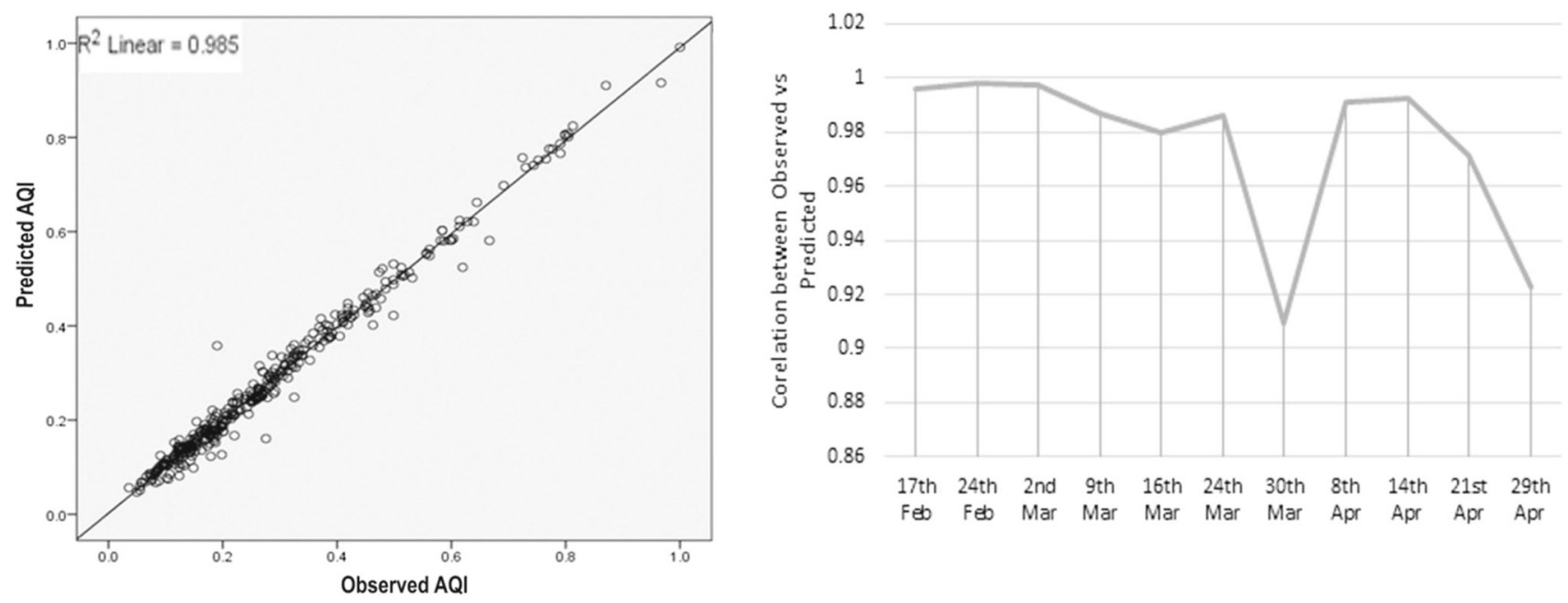

Fig. 7 Accuracy of the model using observed versus predicted values

Fig. 8 Importance of the variable in ANN model

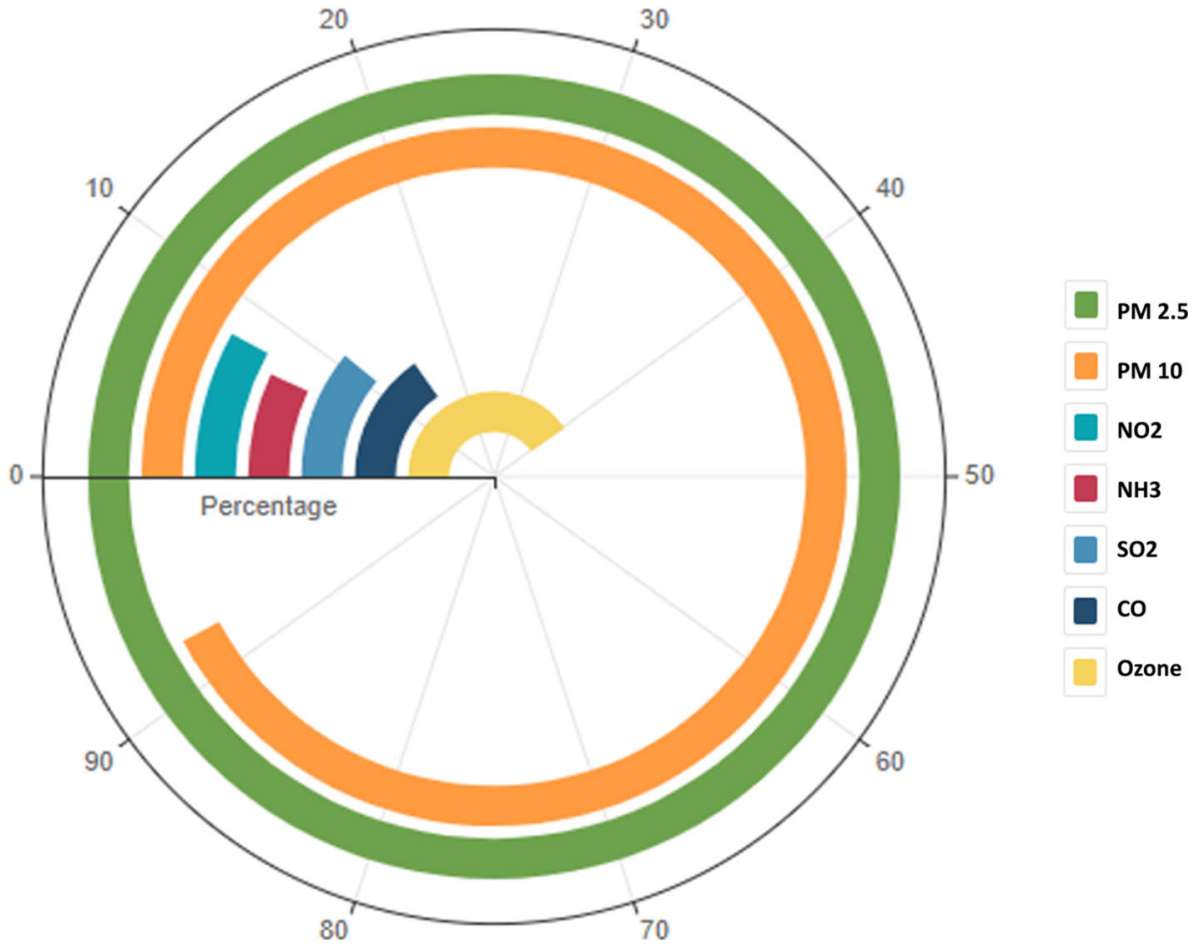

et al. 2020a although the correlation values with maximum temperature were much lower.

Further, previous studies have found that deaths from asthma attack, acute respiratory inflammation, and cardio respiratory diseases are associated with prolonged interaction with polluted air (Schwartz and Dockery 1992; Dockery and Pope 1994) and causing 4.6 millions of deaths per year around the world (Lelieveld et al. 2015, 2019; Cohen et al. 2017). In the post-lockdown phase, there is a substantial drop in daily average $\mathrm{PM}_{10}, \mathrm{PM}_{2.5}, \mathrm{NO}_{2}$, and $\mathrm{SO}_{2}$ levels (Kumari and Toshniwal 2020a). In the postlockdown phase, meanwhile, the proportion of $\mathrm{O}_{3}$ rose.
$\mathrm{PM}_{10}$ levels were within National Ambient Air Quality Standards (NAAQS) on a daily basis (Aneja et al. 2001). Besides this medical profile and the patients' age structure died from COVID-19 found that all the age categories are susceptible to COVID-19, but the mortality rate increases with increasing age combined with pre-existing medical conditions related to heart disease diabetes and asthma (WHO 2020). As well as, Wu et al. 2020 found that in the USA, COVID-19 death is related to prolonged exposure to the $\mathrm{PM}_{2.5}$. Therefore, Contini and Costabile 2020 rightly mentioned that air quality can be considered as a factor affecting the respiratory system of the human body and 
Table 1 Network information of ANN

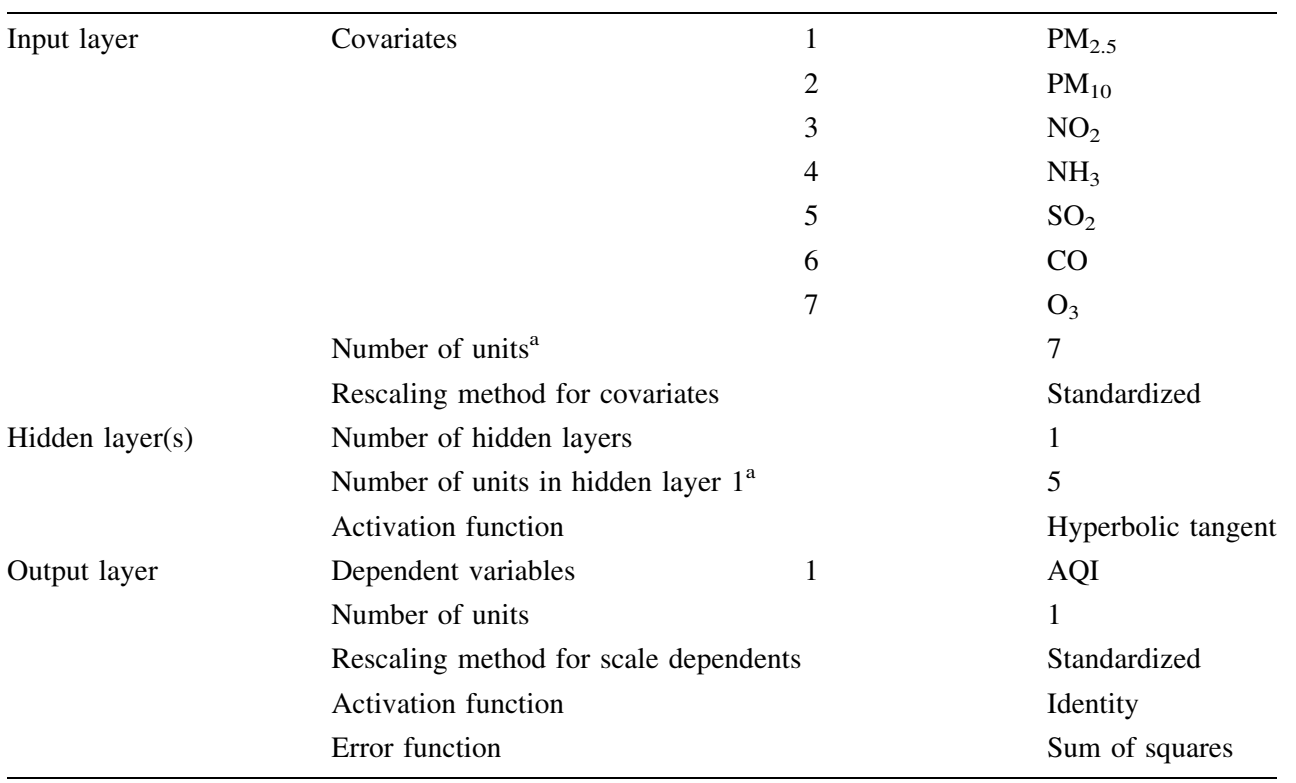

${ }^{a}$ Excluding the bias unit

Table 2 Spearman rho correlation coefficient of selected variables

\begin{tabular}{|c|c|c|c|c|c|c|c|c|c|}
\hline & $\begin{array}{l}\text { Daily new } \\
\text { cases }\end{array}$ & $\begin{array}{l}\text { Daily new } \\
\text { deaths }\end{array}$ & $\begin{array}{l}\text { Total } \\
\text { deaths }\end{array}$ & $\begin{array}{l}\text { Mortality } \\
\text { rate }\end{array}$ & $\begin{array}{l}\text { Maximum } \\
\text { temperature }\end{array}$ & $\begin{array}{l}\text { Minimum } \\
\text { temperature }\end{array}$ & $\begin{array}{l}\text { Average } \\
\text { temperature }\end{array}$ & $\begin{array}{l}\text { Average } \\
\text { rainfall }\end{array}$ & $\begin{array}{l}\text { Air } \\
\text { quality }\end{array}$ \\
\hline $\begin{array}{l}\text { Daily new } \\
\text { cases }\end{array}$ & 1.000 & $.885^{* *}$ & $.863 * *$ & $.885 * *$ & $.651 * *$ & $.379 * *$ & $.603 * *$ & $.284 *$ & $-.804 * *$ \\
\hline Total deaths & $.885^{* *}$ & 1.000 & $.901 * *$ & $1.000 * *$ & $.682 * *$ & $.315 * *$ & $.608 * *$ & $.259 *$ & $-.826^{* *}$ \\
\hline $\begin{array}{c}\text { Daily new } \\
\text { deaths }\end{array}$ & $.863^{* *}$ & $.901 * *$ & 1.000 & $.901 * *$ & $.817 * *$ & $.376^{* *}$ & $.744 * *$ & $.360 * *$ & $-.916^{* *}$ \\
\hline Mortality rate & $.885^{* *}$ & $1.000 * *$ & $.901 * *$ & 1.000 & $.682 * *$ & $.315 * *$ & $.608 * *$ & $.259 *$ & $-.826^{* *}$ \\
\hline $\begin{array}{l}\text { Maximum } \\
\text { temperature }\end{array}$ & $.651^{* *}$ & $.682 * *$ & $.817 * *$ & $.682 * *$ & 1.000 & $.477 * *$ & $.914^{* *}$ & $.376 * *$ & $-.760 * *$ \\
\hline $\begin{array}{l}\text { Minimum } \\
\text { temperature }\end{array}$ & $.379^{* *}$ & $.315^{* *}$ & $.376^{* *}$ & $.315^{* *}$ & $.477 * *$ & 1.000 & $.748 * *$ & .153 & $-.413^{* *}$ \\
\hline $\begin{array}{l}\text { Average } \\
\text { temperature }\end{array}$ & $.603 * *$ & $.608^{* *}$ & $.744 * *$ & $.608 * *$ & $.914 * *$ & $.748 * *$ & 1.000 & $.328 * *$ & $-.719^{* *}$ \\
\hline $\begin{array}{l}\text { Average } \\
\text { rainfall }\end{array}$ & $.284 *$ & $.259 *$ & $.360 * *$ & $.259 *$ & $.376^{* *}$ & .153 & $.328 * *$ & 1.000 & $-.391 * *$ \\
\hline Air quality & $-.804^{* *}$ & $-.826^{* *}$ & $-.916^{* *}$ & $-.826 * *$ & $-.760 * *$ & $-.413^{* *}$ & $-.719 * *$ & $-.391 * *$ & 1.000 \\
\hline
\end{tabular}

***, **, and * are the significant at the $1 \%, 5 \%$, and $10 \%$ levels of significance, respectively

increasing mortality rates. Besides this, the quality of air is severely related to human activities (Donahue 2018) and we can infer that the interaction among the people is also very high in this area, thereby the probability of high infected people as well as high mortality rate around the polluted areas. So, it can be said that climate indicators and air quality are not significantly connected with COVID-19 death cases. Several factors are conspiring to bring pollution levels back to levels seen prior to the COVID-19 pandemic, such as calls from some decision-makers and businesses to reschedule Green New Deal projects, reduce vehicle emissions specifications, and stymie the execution of renewable power and inventory work (Pal et al. 2021b). Apart from this, Singh and Chauhan 2020 stated that during the lockdown, air pollution levels decreased significantly, particularly in Delhi and Kolkata, both of which are renowned to be among India's and the world's most polluted cities. Apart from this, various studies indicate that there is an improving nature of air quality in association with COVID-19 lockdown in various parts of the world (Balasubramaniam et al. 2020; Kumari and Toshniwal 2020b; Li et al. 2020). Chowdhuri et al. 2021 show that, 
Table 3 Pollutant matter and gases before and after lockdown in India 2020 (Source: National Air quality Index portal, Central Pollution Control Board, Govt. of India, 2020)

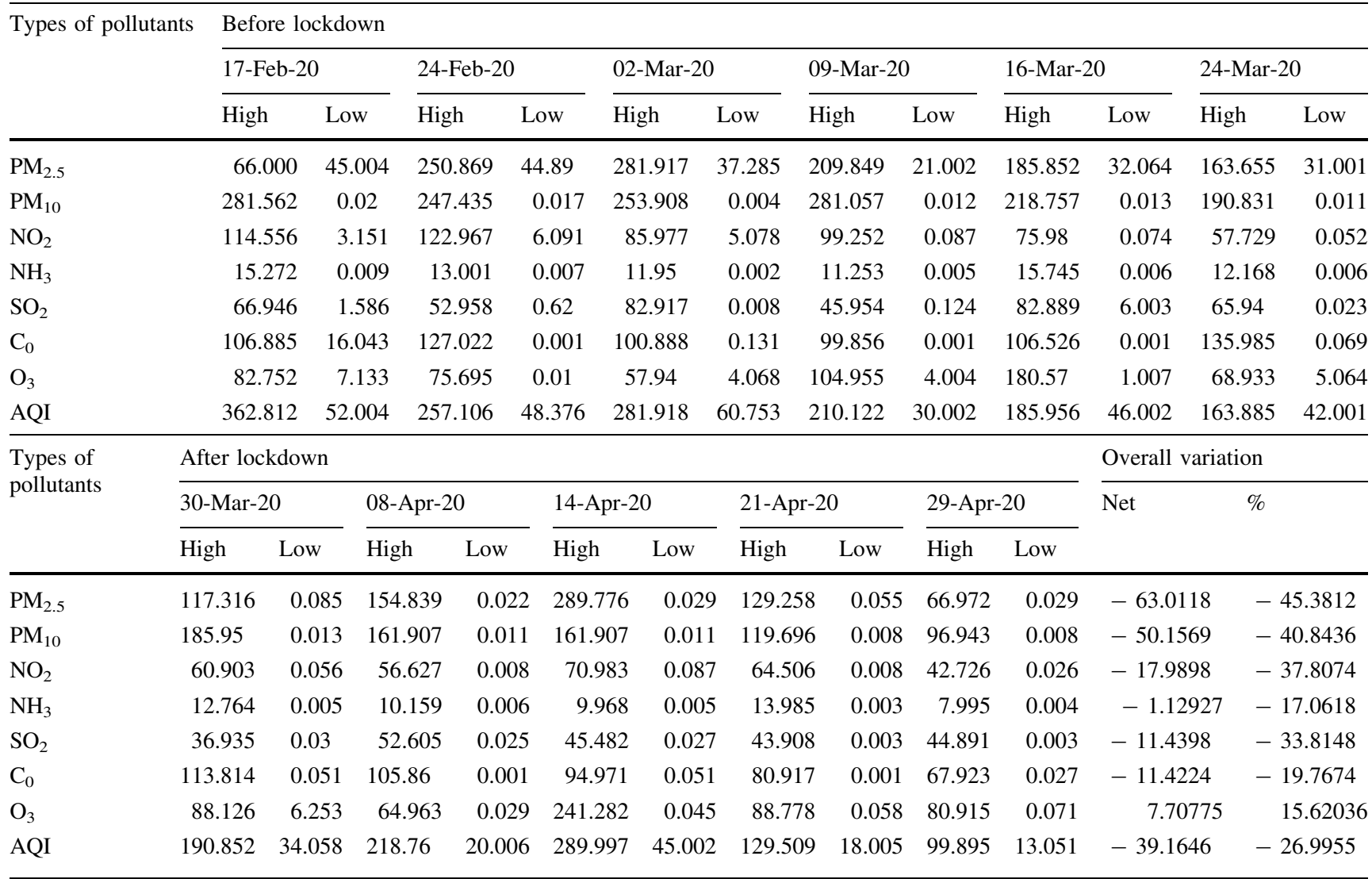

Fig. 9 Variability of temperature in before and during lockdown periods

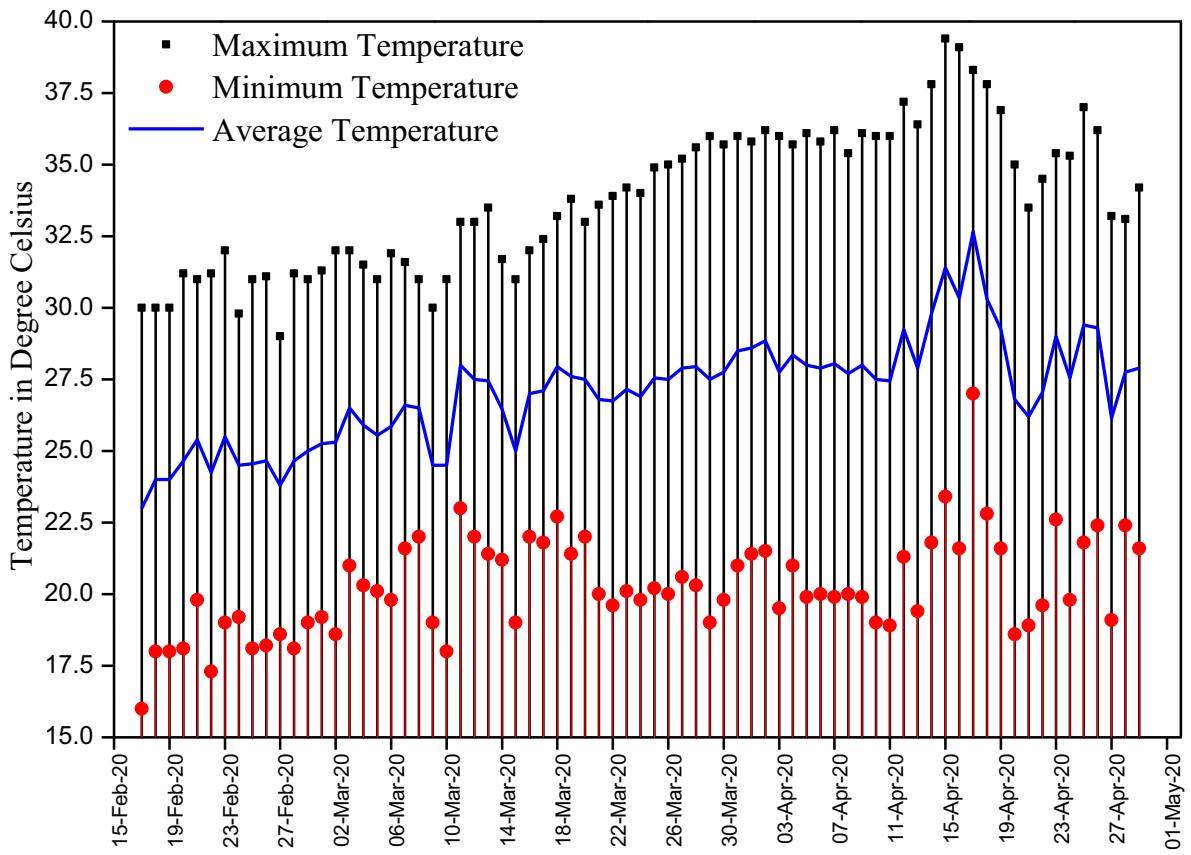


Fig. 10 Trend of positive COVID-19 cases in different temporal periods

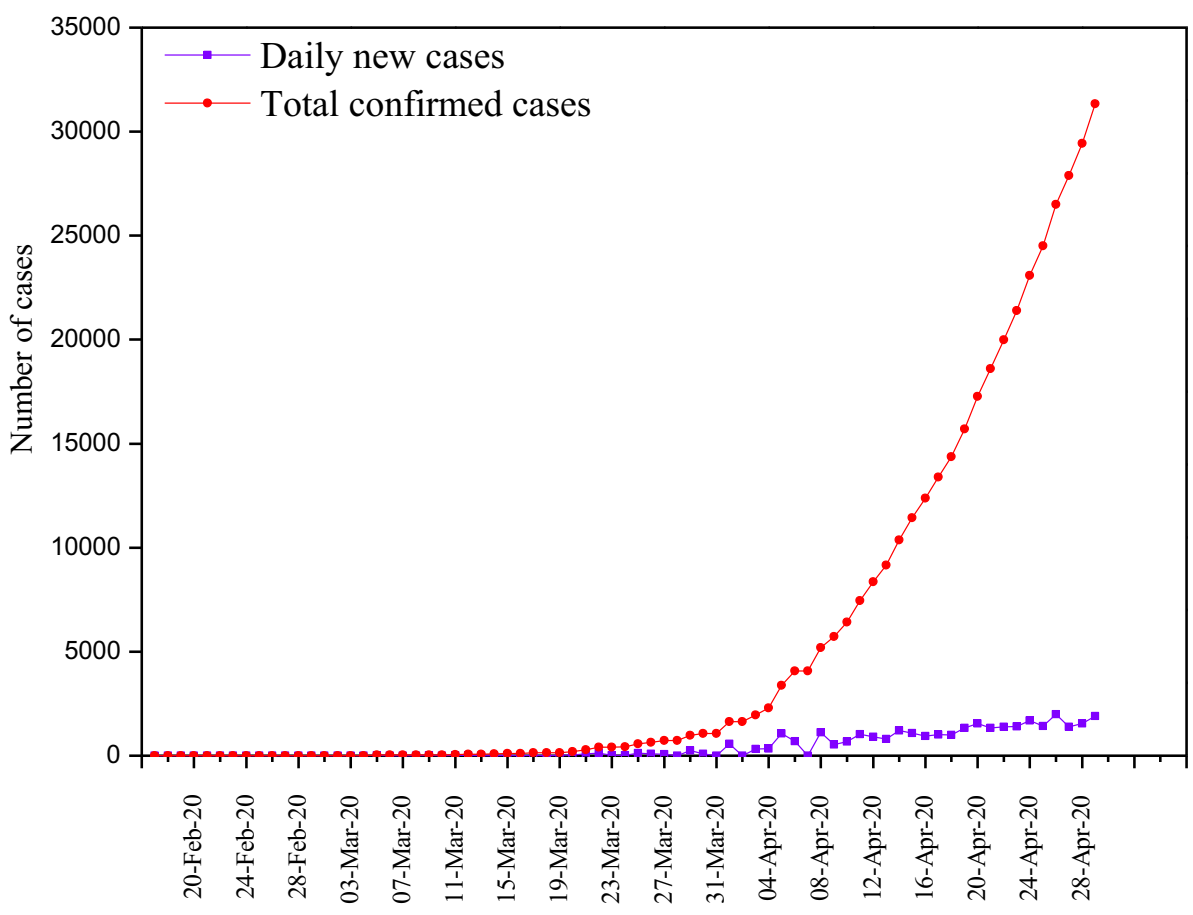

Table 4 Kendal tau correlation coefficient of selected variables

\begin{tabular}{|c|c|c|c|c|c|c|c|c|c|}
\hline & $\begin{array}{l}\text { Daily new } \\
\text { cases }\end{array}$ & $\begin{array}{l}\text { Daily new } \\
\text { deaths }\end{array}$ & $\begin{array}{l}\text { Total } \\
\text { deaths }\end{array}$ & $\begin{array}{l}\text { Mortality } \\
\text { rate }\end{array}$ & $\begin{array}{l}\text { Maximum } \\
\text { temperature }\end{array}$ & $\begin{array}{l}\text { Minimum } \\
\text { temperature }\end{array}$ & $\begin{array}{l}\text { Average } \\
\text { temperature }\end{array}$ & $\begin{array}{l}\text { Average } \\
\text { rainfall }\end{array}$ & $\begin{array}{l}\text { Air } \\
\text { quality }\end{array}$ \\
\hline $\begin{array}{l}\text { Daily new } \\
\text { cases }\end{array}$ & 1.000 & $.772 * *$ & $.761 * *$ & $.772 * *$ & $.506 * *$ & $.259 * *$ & $.472 * *$ & $.204 *$ & $-.689 * *$ \\
\hline Total deaths & $.772 * *$ & 1.000 & $.812 * *$ & $1.000 * *$ & $.535^{* *} *$ & $.226 * *$ & $.467 * *$ & $.181 *$ & $-.691 * *$ \\
\hline $\begin{array}{l}\text { Daily new } \\
\text { deaths }\end{array}$ & $.761 * *$ & $.812 * *$ & 1.000 & $.812 * *$ & $.659 * *$ & $.265 * *$ & $.579 * *$ & $.244 * *$ & $-.824 * *$ \\
\hline Mortality rate & $.772 * *$ & $1.000 * *$ & $.812 * *$ & 1.000 & $.535^{* *}$ & $.226 * *$ & $.467 * *$ & $.181 *$ & $-.691 * *$ \\
\hline $\begin{array}{l}\text { Maximum } \\
\text { temperature }\end{array}$ & $.506^{* *}$ & $.535^{* *}$ & $.659 * *$ & $.535^{* *}$ & 1.000 & $.341 * *$ & $.773 * *$ & $.264 * *$ & $-.571 * *$ \\
\hline $\begin{array}{l}\text { Minimum } \\
\text { temperature }\end{array}$ & $.259 * *$ & $.226 * *$ & $.265 * *$ & $.226 * *$ & $.341 * *$ & 1.000 & $.584 * *$ & .113 & $-.279 * *$ \\
\hline $\begin{array}{l}\text { Average } \\
\text { temperature }\end{array}$ & $.472 * *$ & $.467 * *$ & $.579 * *$ & $.467 * *$ & $.773 * *$ & $.584 * *$ & 1.000 & $.231 * *$ & $-.542 * *$ \\
\hline $\begin{array}{l}\text { Average } \\
\text { rainfall }\end{array}$ & $.204 *$ & $.181 *$ & $.244 * *$ & $.181 *$ & $.264 * *$ & .113 & $.231 * *$ & 1.000 & $-.266^{* *}$ \\
\hline Air quality & $-.689 * *$ & $-.691 * *$ & $-.824 * *$ & $-.691 * *$ & $-.571 * *$ & $-.279 * *$ & $-.542 * *$ & $-.266^{* *}$ & 1.000 \\
\hline
\end{tabular}

$* * *, * *$, and $*$ are the significant at the $1 \%, 5 \%$, and $10 \%$ levels of significance, respectively

due to the spread of the COVID-19 pandemic, the Indian government implemented a lockdown period (which began on March 24, 2020) during which the concentrations of several contaminants fell considerably. During the lockdown time, the air quality improved and the urban temperature progressively fell attributed to the prevalence of low air pollutants in the environment. During the COVID19 lockdown phase, Chowdhuri et al. 2020 found a significant reduction in pre-monsoon lightening incidence above the Kolkata megacity in India. The COVID-19 epidemic caused a reduction in $\mathrm{PM}_{10}, \mathrm{NO}_{2}, \mathrm{SO}_{2}, \mathrm{O}_{3}$, and aerosol contents in the lower atmosphere, which was the primary reason of the drop in pre-monsoon lightning rates. In this research, apart from the improving air quality in lockdown period we try to estimate the relationship between the climatic conditions and the daily cases. From this, we found that there is no such importance among the climatic variables and COVID-19 daily cases. In previous 
Table 5 Comparative analysis of pollutant matter in India in 2016, 2017, 2018, 2019, and 2020 ( Source: National Air quality Index portal, Central Pollution Control Board, Govt. of India, 2020)

\begin{tabular}{|c|c|c|c|c|c|c|c|c|c|c|c|c|}
\hline \multirow{3}{*}{\multicolumn{2}{|c|}{ Types of pollutants }} & \multicolumn{11}{|c|}{ Before lockdown } \\
\hline & & \multicolumn{3}{|c|}{ 17-Feb-16 } & \multicolumn{3}{|c|}{$17-F e b-17$} & \multicolumn{3}{|c|}{ 17-Feb-18 } & \multicolumn{2}{|c|}{ 17-Feb-19 } \\
\hline & & \multicolumn{2}{|l|}{ High } & Low & \multicolumn{2}{|l|}{ High } & Low & \multicolumn{2}{|l|}{ High } & Low & High & Low \\
\hline \multicolumn{2}{|l|}{$\mathrm{PM}_{2.5}$} & 340.231 & & 36.027 & \multicolumn{2}{|c|}{341.881} & 36.98 & \multicolumn{2}{|c|}{343.003} & 37.131 & 340.231 & 36.027 \\
\hline $\mathrm{PM}_{10}$ & & 263.81 & \multicolumn{2}{|c|}{0.013} & \multicolumn{2}{|c|}{263.814} & 0.687 & \multicolumn{2}{|c|}{263.817} & 1.687 & 263.818 & 0.013 \\
\hline $\mathrm{NO}_{2}$ & & 114.311 & \multicolumn{2}{|c|}{3.285} & \multicolumn{2}{|c|}{114.808} & 3.13 & \multicolumn{2}{|c|}{114.719} & 3.152 & 114.724 & 3.157 \\
\hline $\mathrm{NH}_{3}$ & & 13.189 & \multicolumn{2}{|c|}{0.007} & \multicolumn{2}{|c|}{15.227} & 0.009 & \multicolumn{2}{|c|}{15.228} & 0.009 & 15.291 & 0.009 \\
\hline $\mathrm{SO}_{2}$ & & 66.945 & \multicolumn{2}{|c|}{1.583} & \multicolumn{2}{|c|}{66.934} & 1.856 & 66.9 & & 1.551 & 66.946 & 2.003 \\
\hline $\mathrm{C}_{0}$ & & 106.891 & & 053 & 106.892 & & 16.054 & 106.9 & & 16.054 & 107.92 & 16.054 \\
\hline $\mathrm{O}_{3}$ & & 83.251 & & 191 & 84.451 & & 7.228 & 85.8 & & 7.213 & 85.981 & 7.256 \\
\hline AQI & & 362.812 & & 011 & 362.803 & & 73.012 & 362.78 & & 73.012 & 361.134 & 73.342 \\
\hline Types of & After loc & kdown & & & & & & & & & Overall variatic & \\
\hline & 30-Mar- & & 08-Apr- 2 & & 14-Apr-2 & & 21-Apr-2 & & 29-Apr & & Net & $\%$ \\
\hline & High & Low & High & Low & High & Low & High & Low & High & Low & & \\
\hline $\mathrm{PM}_{2.5}$ & 117.316 & 0.085 & 154.839 & 0.022 & 289.776 & 0.029 & 129.258 & 0.055 & 66.972 & 0.029 & -113.101 & -59.861 \\
\hline $\mathrm{PM}_{10}$ & 185.95 & 0.013 & 161.907 & 0.011 & 161.907 & 0.011 & 119.696 & 0.008 & 96.943 & 0.008 & -59.562 & -45.0519 \\
\hline $\mathrm{NO}_{2}$ & 60.903 & 0.056 & 56.627 & 0.008 & 70.983 & 0.087 & 64.506 & 0.008 & 42.726 & 0.026 & -29.3178 & -49.7664 \\
\hline $\mathrm{NH}_{3}$ & 12.764 & 0.005 & 10.159 & 0.006 & 9.968 & 0.005 & 13.985 & 0.003 & 7.995 & 0.004 & -1.88173 & -25.5283 \\
\hline $\mathrm{SO}_{2}$ & 36.935 & 0.03 & 52.605 & 0.025 & 45.482 & 0.027 & 43.908 & 0.003 & 44.891 & 0.003 & -11.9545 & -34.8067 \\
\hline $\mathrm{C}_{0}$ & 113.814 & 0.051 & 105.86 & 0.001 & 94.971 & 0.051 & 80.917 & 0.001 & 67.923 & 0.027 & -15.2424 & -24.7425 \\
\hline $\mathrm{O}_{3}$ & 88.126 & 6.253 & 64.963 & 0.029 & 241.282 & 0.045 & 88.778 & 0.058 & 80.915 & 0.071 & 11.004 & 23.8968 \\
\hline AQI & 190.852 & 34.058 & 218.76 & 20.006 & 289.997 & 45.002 & 129.509 & 18.005 & 99.895 & 13.051 & -111.825 & -51.3575 \\
\hline
\end{tabular}

researches, it was indicated that the lower temperature is most favorable for COVID-19 cases. But the outcomes from our study are totally different which indicate that there is no such importance of climatic factors in COVID19 cases (Table 5).

\section{Conclusion}

It can be stated that the COVID-19 pandemic-induced lockdown imposed significant restriction on human activities which has reduced emissions of the pollutants from commercial sectors in India. The much-needed lockdown effect on concentrations of seven air pollutants and climate indicators from February 17 to April 29, 2020, at 223 locations in different stations across the country shows significant reductions. The study has found that among all pollutants, $\mathrm{PM}_{10}$ and $\mathrm{PM}_{2.5}$ recorded the highest decline accompanied by $\mathrm{NO}_{2}, \mathrm{SO}_{2}, \mathrm{NH}_{3}$, and $\mathrm{CO}$. The concentrations of $\mathrm{PM}_{10}$ and $\mathrm{PM}_{2.5}$ are declined by approximately $-40.84 \%$ and $-45.38 \%$, respectively, relative to the previous four years across the country. Besides, an improvement in $\mathrm{O}_{3}$ has been observed (15.62\%) in most regions, which can be due to the drop in particulate matter in relation to the decline in $\mathrm{NO}_{\mathrm{x}}$. It is obvious from the outcomes that the lockdown implementation has contributed to a major change in air quality and could be placed into action as an additional way of decreasing emissions from different sources. Moreover, the findings will be the key issue for decision-makers to implement necessary measures to control the air pollutants and mortality rate.

The present study would have a huge impact on postpandemic crisis management of air quality, especially for megacities. The policymakers would have the opportunities to redesign the existing air quality regulatory mechanism. The study would provide concrete evidence on how the human anthropogenic activity has affected the composition of the lower atmosphere. Apart from this, the neutrality of climatic variables on COVID-19 outbreak and its associated daily cases has also been established from this research. In Indian condition (our research findings), there is a positive relationship between the increasing air temperature and the total number of Corona positive cases. However, some studies in other parts of the world have found that there is a significant relationship between 
changing air temperature and COVID-19 outbreak. Moreover, spread of others SARS virus was also affected by the air temperature. Therefore, the present study does a statistical experiment based on available data of mentioned variables in India. It has been found that temperature is not an important determining element for increasing COVID19 positive cases. This particular direction of situations related to the outbreak should be helpful to the future researches in relation to this field. The new wave of COVID-19 has already faced by different parts of the world, and India is considered one of the severe countries in this perspective. And the third wave has also been found in the western part of the India. So, the efficient research and its outcome are needed to tackle the new stream of this virus in optimal way.

Author contributions All the authors have substantial contributions to the conception and design of the work.

\section{Declarations}

Conflict of interest The authors declare that they have no conflict of interest.

Ethical approval This article does not contain any studies with human participants or animals performed by any of the authors.

\section{References}

Ahmadi M, Shari A, Dorosti S et al (2020) Investigation of effective climatology parameters on COVID-19 outbreak in Iran. Sci Total Environ. https://doi.org/10.1016/j.scitotenv.2020.138705

Aneja VP, Agarwal A, Roelle PA et al (2001) Measurements and analysis of criteria pollutants in New Delhi, India. Environ Int 27:35-42. https://doi.org/10.1016/S0160-4120(01)00051-4

Apostolopoulos ID, Mpesiana TA (2020) Covid-19: automatic detection from $\mathrm{x}$-ray images utilizing transfer learning with convolutional neural networks. Phys Eng Sci Med 43:635-640

Balakrishnan K (2019) The impact of air pollution on deaths, disease burden, and life expectancy across the states of India : the Global Burden of Disease Study 2017. Lancet Planet Health 3:26-39. https://doi.org/10.1016/S2542-5196(18)30261-4

Balasubramaniam D, Kanmanipappa C, Shankarlal B, Saravanan M (2020) Assessing the impact of lockdown in US, Italy and France-What are the changes in air quality? Energ Source Part A Recovery Util Environ Effects 0:1-11. https://doi.org/10.1080/ 15567036.2020.1837300

Bashir MF, Ma B, Bilal, et al (2020a) Correlation between climate indicators and COVID-19 pandemic in New York, USA. Sci Total Environ 728:138835. https://doi.org/10.1016/j.scitotenv. 2020.138835

Bashir MF, Ma B, Komal B et al (2020b) Science of the Total Environment Correlation between climate indicators and COVID-19 pandemic in New. Sci Total Environ 728:138835. https://doi.org/10.1016/j.scitotenv.2020.138835

Boccaletti S, Ditto W, Mindlin G, Atangana A (2020) Modeling and forecasting of epidemic spreading: the case of Covid-19 and beyond. Chaos Solitons Fractals 135:109794. https://doi.org/10. 1016/j.chaos.2020.109794

Briz-Redón Á, Serrano-Aroca Á (2020) The effect of climate on the spread of the COVID-19 pandemic: a review of findings, and statistical and modelling techniques. Prog Phys Geogr Earth Environ 44:591-604. https://doi.org/10.1177/ 0309133320946302

Castillo O, Melin P (2020) Forecasting of COVID-19 time series for countries in the world based on a hybrid approach combining the fractal dimension and fuzzy logic. Chaos, Solitons Fractals 140:110242. https://doi.org/10.1016/j.chaos.2020.110242

Castillo O, Melin P (2021) A novel method for a COVID-19 classification of countries based on an intelligent fuzzy fractal approach. Healthcare 9:196. https://doi.org/10.3390/ healthcare 9020196

Census of India (2011) West Bengal Census Handbook

Chen B, Liang H, Yuan X, et al (2020) Roles of meteorological conditions in COVID-19 transmission on a worldwide scale. MedRxiv

Chin AWH, Chu JTS, Perera MRA et al (2020) Stability of SARSCoV-2 in different environmental conditions. Lancet Microbe 1:e10. https://doi.org/10.1016/S2666-5247(20)30003-3

Chowdhuri I, Pal SC, Arabameri A et al (2021) Have any effect of COVID-19 lockdown on environmental sustainability? A study from most polluted metropolitan area of India. Stoch Environ Res Risk Assess. https://doi.org/10.1007/s00477-021-02019-8

Chowdhuri I, Pal SC, Saha A et al (2020) Significant decrease of lightning activities during COVID-19 lockdown period over Kolkata megacity in India. Sci Total Environ 747:141321. https://doi.org/10.1016/j.scitotenv.2020.141321

Cohen AJ, Brauer M, Burnett R et al (2017) Estimates and 25-year trends of the global burden of disease attributable to ambient air pollution: an analysis of data from the Global Burden of Diseases Study 2015. Lancet 389:1907-1918. https://doi.org/10. 1016/S0140-6736(17)30505-6

Contini D, Costabile F (2020) Does air pollution influence COVID-19 outbreaks? Atmosphere 11:377. https://doi.org/10.3390/ atmos 11040377

Cracknell MJ, Reading AM (2014) Geological mapping using remote sensing data: a comparison of five machine learning algorithms, their response to variations in the spatial distribution of training data and the use of explicit spatial information. Comput Geosci 63:22-33

Dalziel BD, Kissler S, Gog JR et al (2018a) Urbanization and humidity shape the intensity of influenza epidemics in U.S. cities. Science 79:75-79

Dalziel BD, Kissler S, Gog JR et al (2018b) Urbanization and humidity shape the intensity of influenza epidemics in US cities. Science 362:75-79

Dockery DW, Pope CA (1994) Acute respiratory effects of particulate air pollution. Annu Rev Public Health 15:107-132

Donahue NM (2018) Air pollution and air quality. In: Török B, Dransfield T (eds) Green chemistry. Elsevier, pp 151-176

ESA (2020) Coronavirus lockdown leading to drop in pollution across Europe

Garaga R, Sahu SK, Kota SH (2018) A review of air quality modeling studies in India: local and regional scale. Curr Pollut Rep 4:59-73

Ghorani-Azam A, Riahi-Zanjani B, Balali-Mood M (2016) Effects of air pollution on human health and practical measures for prevention in Iran. J Res Med Sci 21:65. https://doi.org/10. 4103/1735-1995.189646

Gurjar BR, Ravindra K, Singh A (2016) Air pollution trends over Indian megacities and their local-to-global implications. Atmos Environ 142:475-495. https://doi.org/10.1016/j.atmosenv.2016. 06.030 
Hewitson BC, Crane RG (1994) Neural nets: applications in geography: applications for geography. Springer

Huang X, Ding A, Gao J et al (2021) Enhanced secondary pollution offset reduction of primary emissions during COVID-19 lockdown in China. Nat Sci Rev. https://doi.org/10.1093/nsr/ nwaa 137

Jain AK, Mao J, Mohiuddin KM (1996) Artificial neural networks: a tutorial. Computer 29:31-44

Kamyotra JS, Sinha D (2016) CPCB bulletin. Central Pollution Control Board, Delhi, pp 20-21

Kendall MG (1975) Kendall rank correlation methods. Griffin, London

Kumari P, Toshniwal D (2020a) Impact of lockdown measures during COVID-19 on air quality-a case study of India. Int J Environ Health Res. https://doi.org/10.1080/09603123.2020.1778646

Kumari P, Toshniwal D (2020b) Impact of lockdown on air quality over major cities across the globe during COVID-19 pandemic. Urban Climate 34:100719

Lelieveld J, Evans JS, Fnais M et al (2015) The contribution of outdoor air pollution sources to premature mortality on a global scale. Nature 525:367-371

Lelieveld J, Klingmüller K, Pozzer A et al (2019) Cardiovascular disease burden from ambient air pollution in Europe reassessed using novel hazard ratio functions. Eur Heart J 40:1590-1596. https://doi.org/10.1093/eurheartj/ehz135

Levine E, Kimes D, Sigillito V (1996) Classifying soil structure using neural networks. Ecol Model 92:101-108

Li L, Li Q, Huang L et al (2020) Air quality changes during the COVID-19 lockdown over the Yangtze River Delta Region: an insight into the impact of human activity pattern changes on air pollution variation. Sci Total Environ 732:139282

Licznar P, Nearing M (2003) Artificial neural networks of soil erosion and runoff prediction at the plot scale. CATENA 51:89-114

Ma Y, Zhao Y, Liu J et al (2020) Effects of temperature variation and humidity on the death of COVID-19 in Wuhan, China. Sci Total Environ 724:138226. https://doi.org/10.1016/j.scitotenv.2020. 138226

Mahato S, Pal S, Ghosh KG (2020) Effect of lockdown amid COVID19 pandemic on air quality of the megacity Delhi, India. Sci Total Environ. https://doi.org/10.1016/j.scitotenv.2020.139086

Majumdar D, Purohit P, Bhanarkar AD et al (2020) Managing future air quality in megacities: emission inventory and scenario analysis for the Kolkata Metropolitan City, India 1. Atmos Environ 222:117135. https://doi.org/10.1016/j.atmosenv.2019. 117135

Mann HB (1945) Nonparametric tests against trend. Econom J Econom Soc 13:245-259

Melin P, Monica JC, Sanchez D, Castillo O (2020a) Multiple ensemble neural network models with fuzzy response aggregation for predicting COVID-19 time series: the case of Mexico. Healthcare 8:181. https://doi.org/10.3390/healthcare8020181

Melin P, Monica JC, Sanchez D, Castillo O (2020b) Analysis of spatial spread relationships of coronavirus (COVID-19) pandemic in the world using self organizing maps. Chaos Solitons Fractals 138:109917. https://doi.org/10.1016/j.chaos.2020. 109917

NASA (2020) Airborne nitrogen dioxide plummets over China. NASA Earth Observatory

Ott WR (1978) Environmental indices: theory and practice

Pal SC, Chakrabortty R, Roy P et al (2021a) Changing climate and land use of 21 st century influences soil erosion in India. Gondwana Res 94:164-185. https://doi.org/10.1016/j.gr.2021. 02.021

Pal SC, Chowdhuri I, Saha A et al (2021b) Improvement in ambientair-quality reduced temperature during the COVID-19 lockdown period in India. Environ Dev Sustain 23:9581-9608. https://doi. org/10.1007/s10668-020-01034-z

Pant S, Singh M, Ravichandiran V et al (2020) Peptide-like and small-molecule inhibitors against Covid-19. J Biomol Struct Dyn 39:1-10

Poole L (2020) Seasonal influences on the spread of SARS-CoV-2 (COVID19), causality, and forecastabililty (3-15-2020). Causality, and Forecastabililty (3-15-2020) (March 15, 2020)

Sajadi MM, Habibzadeh P, Vintzileos A et al (2020) Temperature, humidity, and latitude analysis to estimate potential spread and seasonality of coronavirus disease 2019 (COVID-19). JAMA Netw Open 3:e2011834-e2011834

Santosh KC (2020) AI-driven tools for coronavirus outbreak: need of active learning and cross-population train/test models on multitudinal/multimodal data. J Med Syst 44:93. https://doi.org/10. 1007/s10916-020-01562-1

Sarkodie SA, Owusu PA (2020) Investigating the cases of novel coronavirus disease (COVID-19) in China using dynamic statistical techniques. Heliyon 6:e03747. https://doi.org/10. 1016/j.heliyon.2020.e03747

Schwartz J, Dockery DW (1992) Increased mortality in philadelphia associated with daily air pollution concentrations. Am Rev Respir Dis 145:600-604. https://doi.org/10.1164/ajrccm/145.3. 600

Sharma S, Zhang M, Gao J et al (2020) Science of the Total Environment Effect of restricted emissions during COVID-19 on air quality in India. Sci Total Environ 728:138878. https://doi. org/10.1016/j.scitotenv.2020.138878

Shi P, Dong Y, Yan H et al (2020) Impact of temperature on the dynamics of the COVID-19 outbreak in China. Sci Total Environ 728:138890. https://doi.org/10.1016/j.scitotenv.2020.138890

Singh RP, Chauhan A (2020) Impact of lockdown on air quality in India during COVID-19 pandemic. Air Qual Atmos Health 13:921-928. https://doi.org/10.1007/s11869-020-00863-1

Sun T, Wang Y (2020) Modeling COVID-19 epidemic in Heilongjiang province. China Chaos Solitons Fractals 138:109949. https://doi.org/10.1016/j.chaos.2020.109949

Swamee PK, Tyagi A (1999) Formation of an air pollution index. J Air Waste Manag Assoc 49:88-91

Tan Y-J, Lim SG, Hong W (2005) Characterization of viral proteins encoded by the SARS-coronavirus genome. Antiviral Res 65:69-78

Taylor JM (1987) Kendall's and Spearman's correlation coefficients in the presence of a blocking variable. Biometrics 43:409-416

Tobías A, Carnerero C, Reche C et al (2020) Changes in air quality during the lockdown in Barcelona (Spain) one month into the SARS-CoV-2 epidemic. Sci Total Environ 726:138540. https:// doi.org/10.1016/j.scitotenv.2020.138540

Tzampoglou P, Loukidis D (2020) Investigation of the importance of climatic factors in COVID-19 worldwide intensity. Int J Environ Res Public Health 17:7730. https://doi.org/10.3390/ ijerph17217730

Van Doremalen N, Bushmaker T, Morris DH et al (2020) Aerosol and surface stability of SARS-CoV-2 as compared with SARS-CoV1. N Engl J Med 382:1564-1567

Wang Y, Wang Y, Chen Y, Qin Q (2020) Unique epidemiological and clinical features of the emerging 2019 novel coronavirus pneumonia (COVID-19) implicate special control measures. J Med Virol 92:568-576

Wright R (2020) The world's largest coronavirus lockdown is having a dramatic impact on pollution in India. CNN

Wu X, Nethery RC, Sabath BM et al (2020) Exposure to air pollution and COVID-19 mortality in the United States. medRxiv

Xu R, Rahmandad H, Gupta M et al (2020) Weather conditions and COVID-19 transmission: estimates and projections. https://doi. org/10.1101/2020.05.05.20092627 
Yao Y, Pan J, Liu Z et al (2020) No association of COVID-19 transmission with temperature or UV radiation in Chinese cities. Eur Respir J 55. https://doi.org/10.1183/13993003.00517-2020

Yunus AP, Masago Y, Hijioka Y (2020) COVID-19 and surface water quality: improved lake water quality during the lockdown. Sci
Total Environ 731:139012. https://doi.org/10.1016/j.scitotenv. 2020.139012

Publisher's Note Springer Nature remains neutral with regard to jurisdictional claims in published maps and institutional affiliations.

\section{Authors and Affiliations}

\section{Rabin Chakrabortty ${ }^{1} \cdot$ Subodh Chandra Pal ${ }^{1}$ (1) Manoranjan Ghosh ${ }^{2} \cdot$ Alireza Arabameri $^{3} \cdot$ Asish Saha $^{1}$. Paramita Roy ${ }^{1} \cdot$ Biswajeet Pradhan ${ }^{4,9,10,11}$ - Ayan Mondal ${ }^{5}$. Phuong Thao Thi Ngo $^{6} \cdot$ Indrajit Chowdhuri $^{1}$. Ali P. Yunus ${ }^{7} \cdot$ Mehebub Sahana $^{8} \cdot$ Sadhan Malik $^{1} \cdot$ Biswajit Das $^{1}$}

Subodh Chandra Pal

geo.subodh@gmail.com

Rabin Chakrabortty

rabingeo8@gmail.com

Manoranjan Ghosh

ghoshmanoranjan.99@gmail.com

Alireza Arabameri

a.arabameri@modares.ac.ir

Asish Saha

asishsaha01@gmail.com

Paramita Roy

paramitaroy95@gmail.com

Biswajeet Pradhan

Biswajeet.Pradhan@uts.edu.au

Ayan Mondal

mondalayan.zoo@gmail.com

Phuong Thao Thi Ngo

Ngotphuongthao5@duytan.edu.vn

Indrajit Chowdhuri

indrajitchowdhuri@gmail.com

Ali P. Yunus

pulpadan.yunusali@nies.go.jp

Mehebub Sahana

mehebub.sahana@manchester.ac.uk

Sadhan Malik

sadhanmalik06@gmail.com

Biswajit Das

biswajitdas1119@gmail.com
1 Department of Geography, The University of Burdwan, Bardhaman, West Bengal, India

2 Centre for Rural Development and Sustainable Innovative Technology, Indian Institute of Technology Kharagpur, Kharagpur, West Bengal, India

3 Department of Geomorphology, Tarbiat Modares University, 14117-13116 Tehran, Iran

4 Centre for Advanced Modelling and Geospatial Information Systems (CAMGIS), Faculty of Engineering and Information Technology, University of Technology Sydney, Ultimo, NSW 2007, Australia

5 Ecology and Environmental Modelling Laboratory, Department of Environmental Science, The University of Burdwan, Burdwan, West Bengal, India

6 Institute of Research and Development, Duy Tan University, Da Nang 550000, Vietnam

7 Centre for Climate Change Adaptation, National Institute for Environmental Studies, Ibaraki 305-8506, Japan

8 School of Environment, Education and Development, University of Manchester, Oxford Road, Manchester M13 9PL, UK

9 Department of Energy and Mineral Resources Engineering, Sejong University, Choongmu-gwan, 209 Neungdong-ro, Gwangjin-gu, Seoul 05006, Korea

10 Center of Excellence for Climate Change Research, King Abdulaziz University, P.O. Box 80234, Jeddah 21589, Saudi Arabia

11 Earth Observation Center, Institute of Climate Change, University Kebangsaan Malaysia, 43600 UKM Bangi, Selangor, Malaysia 